(Aus der deutschen Angenklinik in Prag. Vorstand: Prof. Elschnig.)

\title{
Die Beteiligung des Auges an dem Krankheitsbilde des Xeroderma pigmentosum.
}

\author{
Tron \\ Dr. Rudolf Lederer, \\ Augenarzt in Teplitz-Schönau.
}

Die Veranlassung zu der vorliegenden Arbeit bot ein Fall von Xeroderma pigmentosum, auf den Prof. Elschnig meine Aufmerksamkeit lenkte, und der deshalb von besonderem Interesse ist, weil er sich vermöge der auffallenden Beteiligung der Iris dem von Elschnig selbst beschriebenen und dem aus seiner Klinil von Max veröffentlichten anschließt, während von anderer Seite Fälle mit Veränderungen der Regenbogenhant noch nicht publiziert worden sind.

Der Dragoner Johann S.., im Frieden Feldhiiter, 30 Jahre alt, gibt an, seit dem 7. Lebensjahre immer im Sommer nach dem Baden oder, nachdem er in der Sonne gelegen war, Sommersprossen belkommen za haben, welche im Winter vergingen. Seit dem 17. Lebensjahre blieben sie auch im Winter bestehen, während sich im Sommer die Haut überdies schälte. Seit 5 Jahren bemerkt er, daß die Haut der Nase trocken ist und schrumpft.

Im Jahre 1912 erlitt ex einen Hufschlag an der Nasenwurzel; von März bis Mai entwickelte sich an dieser. Stelle eine Geschwulst, die die Größe eines kleinen Hühnereies erreichte und dann excidiert wurde. In der linearen Narbe, welche zurückblieb, bildete sich ein Jahr später eine Anschwellung, welche nach Durchbruch Eiter entleerte. Die Durchbruchsstelle schloB sich erst nach 2 Jahren.

Im April 1917 rückte der Pat. ein. Während der militärischen Ausbildung wurde er von einer hölzernen Handgranate an der linken Stirn getroffen. Im November ent. zündeten sich die Lidränder, weshalb er ins Spital kam. Hier erkrankte er an einer Lungenentzündung, während welcher am oberen Augenhöhlenrand eineAnschwellung bernerkt wurde, aus welcher sich bei der am 26. Dezember vorgenómmenen Incision Eiter entleerte. Nach Heilung der Wunde entlassen, bemerkte er schon am 6 . Jannar eine neuerliche Anschwellnng, die am 9. incidiert, wiederum Eiter entleerte.

Seit dem Pferdehufschlag waren die Augen in jedem Sommer bis zum Winterbeginn entzündet.

Im 6. und 12. Lebensjahre hat Pat. Augenentzündungen durehgemacht, sonst war er stets gesund, klagt nur über Herzkrämpfe und Kurzatmigkeit.

Pat. hat zwei Brüder and zwei Schwestern, die vollkommen gesund sind, auch in seiner weiteren Verwandtschaft ist von einer ähnlichen Erkrankung der Haut nichts bekannt. Vater und Mutter sind miteinander nicht verwandt.

Es handelt sich um einen mittelgroßen, kräftig gebauten, gut genährten Menschen mit mäßiger Herzhypertrophie und dumpfen Herztönen. Im ganzen Gesicht bis zur Haar- und Bartgrenze - vereinzelt auch auf der behaarten Kopfhaut - finden sich reichliche Pigmentflecke von verschiedener Größe und hellbis kaffeebrauner Farbe, an einzelnen Stellen bis tiefschwarz. Am Hals und Stamm bis zur Nabel- bzw. GesäBhöhe stehen die Pigmentflecke aberaus dicht, so dab 
besonders der Rủcken ein dicht marmoriertes Aussehen hat. An den Unterschenkeln ist die Pigmentation spärlicher, dagegen zeigen sie ebenso wie der Rücken Narben nach Furunculose. Die Haut des Gesichtes zeigt an einzelnen Stellen Erweiterung der oberflächlichen Gefäße und kleine Teleangiektasien, namentlich innerhalb einer kronenstückgroßen Narbe an der Nasenwurzel; im Bereich derselben, sowie in der Nachbarsehaft, rechts bis zum inneren Augenwinkel, links bis über die Mitte des Unterlides hinausreichend ist die Haut weiß, verdünnt, gespannt, trocken. Ebenso am Nasenrücken und den Nasenflügeln, wodurch die Nase ein spitzes Aussehen bekommt. Die Haut der Oberlippe radiär gerunzelt.

In der linken Augengegend befindet sich unter der Haut tine knochenharte Anschwellung, welche entsprechend der äußeren Hälfte des oberen Augenhöhlenrandes am mächtigsten, sich nach oben bis über den Stirnhöcker hinaus, unterhalb des Auges bis zur Höhe des Jochbogens und bis zum Nasenrücken erstreckt. Im allgemeinen ohne scharfe Grenze in die Nachbarschaft übergehend, setzt sich die Geschwulst gegen das Planum temporale ziemlich scharf ab und überragt den oberen Orbitalrand mit einem wulstförmigen, stufenartigen Fortsatz, der auch in die Tiefe der Orbita hinein tastbar ist. Drüsen nicht zu tasten.

Die linke Lidspalte ist beträchtlich niedriger als die rechte. Am Oberlid zwei parallele Incisionsnarben. Das Unterlid ist in seinem äußeren Drittel evertiert ưd der Cilien beraubt. Beiderseits im Lidspaltenbereich die' Bindehautgefäße grob erweitert; zwischen innerem Winkel und dem Hornhautrand zieht ein Narbenstrang, der rechts flügelfellartig den Limbus überragt. Links hat die Bindehaut in der Nachbarschaft der Hornhaut anch temporal ein narbiges Aussehen; die obere Tarsalbindehaut gleichfalls narbig verändert. In den zentralen Teilen der rechten Hornhaut eine verwaschene Macula, sonst die Hornhäute normal.

Am bemerkenswertesten sind die Veränderungen an der Iris, welche beiderseits ungefähr gleich sind. Die Tris ist blau; während in der oberen Hälfte ihre Struktur normal, dicht und fest gefügt erscheint, eine wohl entwickelte, gelblich gefärbte Krause und gut markierte Krypten zeigt, mit gleicher Färbung der sie begrenzenden Bälkchen, ist die untere Hälfte von gleichmäBig mattgrauer Farbe, substanzärmer, von lockerem Gefüge, ohne jede Andeutung einer Kryptenbildang. Die Krause stellenweise ganz unterbrochen, an anderen Stellen durch zickzackförmige, das übrige Niveau stark überragende Bälkchen scharf hervortretend. Doch sind diese Bälkchen von weißer Farbe, überaus dünn, in den peripheren Abzweigungen sich verlierend; einzelne dieser Bälkchen endigen frei und flottieren in der vorderen Kammer. Das übrige Niveau der Iris tritt gegen das der normalen Partien weit zurück, ihr Gewebe setzt sich zusammen aus lockeren, stark gewellten Fasern, welche unter der Lupe den Eindruck von dünnen. Schläuchen machen. Rechte Pupille etwas exzentrisch nach unten außen, Durchm. etwa $4^{1 / 2} \mathrm{~mm}$, unrund, außen unten in dem am stärksten atrophischen Bezirk $1 \frac{1}{2} \mathrm{~mm}$ breite, zackig begrenzte Eversion des Pigmentepithels. Linke Pupille ganz leicht nach unten exzentrisch, $3 \mathrm{~mm}$, Pupillenreaktion beiderseits, rechts mehr, in allen Qualitäten vermindert. Die Iris diascleral nicht durchleuchtbar. Im Augenhintergrund nichts Abnormes. S rechts $=6 / 12$, links $6 / 18$ mit $+1,0 \mathrm{D}$ id.

Am 19. IV. wurde Pat. an der deutschen chirurgischen Klinilk Prof. Schloffer operiert. Das Protokoll besagt: Allgemeine Narkose. Schnitt am oberen Umfang des Musculus orbicularis oculi und Lospräparieren desselben von der Unterlage so weit, daß der Margo supra-orbitalis vollkommen freiliegt. An ihm findet sich ein halbkirsehengroßer Tumor von mäßig harter Konsistenz. Es wird num der ganze Margo, allerdings knapp im Umkreis des Tumors herausgemeißelt; Dabei kommt man mit dem Instrument überall durch harten, also von Tumor noch nicht ergriffenen Knochen. Gegen die Mittellinie zu wird die linke Stimbeinhöhle eroffnet, in der sich ein weiches Gewebe vorfindet, das ziemlich suspekt anf maligne 
Massen ist, das aber ebensogut entzündetes Schleimhautgewebe sein kann. Mit dem scharfen Löffel werden Teile dieses Stirnhöhleninhaltes herausgelöffelt, zwecks histologiseher Untersuchung. Blutstillung, Hautnaht.

26. IV. Entfernung der Nähte, Heilung per primam.

Histologisch: Der Befund eines Carcinoms im Sinne eines Carcinoma solidum. Tumorzellen im Inhalt der Stirnbeinhöhle mit Sicherheit nicht nachweisbar.

Auf die Einzelheiten des Falles möchte ich erst im Zusammenhang mit den anderen bisher veröffentlichten eingehen und hier noch den Auszug aus der mir vom Prof. Elschnig zur Verfügung gestellten Krankengeschichte eines zweiten Falles mitteilen, der zuerst im Jahre 1907 aufgenommen, fünfmal auf der deutschen Augenlklinik in Prag in Behandlung gestanden ist.

Adalbert J., 20 Jahre alt, weloher schon seit langer Zeit Fleoken an seinem Körper hatte, kam zur Klinik wegen einer Augenaffektion, die vor 8-10 Jahren am rechten inneren Augenwinkel als eine "Hautfalte" begonnen hatte, welche das Auge durch ihr Wachstum zu bedecken drohte. Unter ärztlicher Behandlung sohwand sie innerhalb $1 / 2$ Jahres, während ein neuer Herd am Nasenrücken auftrat. Auch hier brachte ärztliche Behandlung Besserung, doch erkrankten andere Stellen an linken Unterlid. Vor einem Jahr anderwärts an beiden Lidern operiert.

Eltern gestorben. 2 Brüder gesund, eine Schwester hat seit Kindheit ähnliche Flecke am ganzen Körper.

Mittelgroß, grazil, mittelmäßig genährt. Über den Lungenspitzen etwas abgeschwächtes Atmen, Herzbefund normal. Hypertrophie der Nasenschleimhaut.

Am Stamm, an den Extremitäten, besonders an den Streckseiten und im Gesicht eine Menge stecknadelkopf- bis linsengroßer runder, den Sommersprossen gleichender Pigmentflecke. Die Nase größtenteils von narbig verändertex Haut bedeckt, am rechten Nasenflïgel einige Defekte. Im gesunden Gebiete dilatierte Gefäße. $1 \mathrm{~cm}$ unter beiden Mundwinkeln harte linsengroße Tumoren, je ein gleicher Tumor vor beiden Ohren, links über dem äußeren Ende der Augenbraue, an der Haargrenze, hinter dem linken Ohrläppchen.

In der Umgebung beider Augen ausgebreitete Narbenbildung, so daß die Hebung des rechten Oberlides etwas, die des linken nur mit Beihilfe des Frontalis in sehr geringem Grade möglich ist, auch passiv nicht mehr.

Rechtes Auge: Das Unterlid vollstândig fehlend, die freiliegende, diffus rote und leicht vertrocknete Bindehaut des Ubergangsteiles durch eine scharfe, narbig eingezogene Linie begrenzt. Aus dem imeren Winkel ragt eine derbe, wulstige, rote Geschwulst von $3 / 4 \mathrm{~cm}$ länge hervor, unter ihr in der Bindehaut zwei rundliche, speckig belegte Substanzverluste, ein ähnlicher kleinerer außen. Augapfel leicht injiziert, die untere Hälfte der Hornhaut makulös getrübt, sonst normal.

linkes Auge: Das Unterlid ebenfalls, fehlend, die Bindehaut stark verkürzt und wulstig, stellenweise mit tiefen Defekten. Der Liddefekt nach außen unten übergehend in einen tiefen bis auf den Orbitalrand reichenden speckig belegten Substanzverlust, von Narbengewebe umgeben. Bulbus nur teilweise in der unteren Hälfte sichtbar. Befund wie rechts.

Am Oberlid zeigt der Lidrand beiderseits in der äußeren Hälfte eine kleine narbige Einziehung. Beiderseits Lagophthalmus. Beweglichkeit nach oben eingeschränkt, links Abduction fast fehlend, Senkung leicht beschränkt.

Nach Exstirpation der Tumoren und Geschwüre an den Augen, bei der sich links die Jochbeinoberfläche miterkrankt zeigte, und Plastik, sowie nach Exstirpation mehrerer Carcinomknoten im Gesichte wurde Pat, mit einem neuaufgetretenen harten Tumor am Nacken am 10. V. 1908 entlassen, kam am 17. XI. 
wieder mit verdächtigen stellenweise exulcerierten Knoten in den zum Teil keloiden Narben im Gesicht und mit linsengroßen indurierten submentalen Drüsen. Am rechten Auge war das Unterlid fast in toto von einem harten scharf begrenzten Tumor eingenommen. Zwischen den starren Lidern nur ein kJeines Stückehen Hornhaut sichtbar, von zarten oberflächlichen Gefäßen durchzogen. $S=0,2$.

Links: Die äußere Hälfte des Unterlides durch ein derbes, vorspringendes Gewebe ersetzt, von dem aus ein Symblepharon den äuBeren unteren Quadranten der Hornhant überspannt. Innen tritt die katarrhaliseh veränderte Bindelaaut als Pterygium über den Hornhautrand. Die Hornhaut unscharf begrenzt, in der Umgebung des Symblepharons und Pterygiums grau getrübt. Beweglichkeit des. Augapfels nach allen Richtungen stark eingeschränkt. $S=0,7$.

Der Tumor am rechten Unterlid wird exstirpiert and durch einen Lappen aus der Stirn ersetzt, rechts der Hautlappen von der Hornhaut abgetragen und ein Bindehautfornix gebildet. Nach Exstirpation des Nackentumors und Radiumbestrahlung des Knotens an der linken Ohrmuschel und am Septum nasi wird Pat. wieder entlassen. Er kommt am 29. X. 1909 mit tief kraterförmig ausgehöhlter Neubildung am Rand des rechten Unterlides mit Einbeziehung der Lid- und Augapfelbindehaut. Der Tumor wird exstirpiert. Während der Wundbehandlung tritt Rezidiv am linken Nasenrïcken und der linken Wange auf und wird bis auf den Knochen entfernt (histologisch: Carcinom).

Mit kleinem Unterliddefekt, starker Beweglichkeitseinschränkung rechts, links mit durch Narbenzug erzeugtem Ektropium der äußeren Hälfte des Unterlids, derber Infiltration der Umgebung des Wangendefektes wird Pat. wieder entlassen. Bei der Wiederaufnahme am 6. VII. 1910 zeigt.er reehts in der Umgebung beider Lider und im Lidwinkel Rezidivtumoren. Das Unterlid fehlend. Links am Unterlid der Lappen geschrumpft in der lateralen Hälfte zwei neue Knoten, durch Bindehautschrumpfung die Bewegungen des Augapfels sehr behindert. Über dem Jochbein bis auf den Knochen reichender Substanzverlust mit wallartig aufgeworfenen Rändern. Exulcerierter Knoten am Tragus. Exstirpation des Wangenrezidivs mit Entfernung des Knochens, temporal einschließlich des Jochbogens, nach unten bis zur. Schleimhaut des Antrum Highmori, nach vorn bis zum Tränenbein. Nur nach hinten wird eine scharfe Begrenzung der Geschwulst nicht erreicht. Nachdem noch Knoten an der rechten Wange, Unterlippe, an Stirn, Kinn und am linken Ohr entfernt worden, wird am rechten Ange der Tumor exstirpiert mit Entfernung eines Teiles desUnterlides, des unteren Augenhöhlenrandes und eines Teiles des Stirnfortsatzes des Oberkiefers, der Defekt durch Mundschleimhaut und durch einen gestielten Lappen von der Brust gedeckt, die einzelnen Knoten im Gesicht und am Ohr mit Radium bestrahlt.

Als Pat. imJuli 1914 wiederkam, war rechts derLappen gnt eingeheilt, unter demselben jedoch carcinoma töse Massen tastbar, die Lider so straff anliegend, daß der BuIbus nur durch Emporheben der Lider mit der Hand zum Sehen verwendet werden konnte. Links faustgroßer Defekt des Jochbeines, Oberkiefers und Bodens der Orbita, vom Bulbus nur ein Stumpf vorhanden, der mit carcinomatösen Massen bedeckt ist, der harte Gaumen zum größten Teil fehlend, so daß die Zunge frei sichtbar ist. Der Rand des großen Defektes hart und infiltriert, von Geschwulstmassen durchsetzt.

Die beiden mitgeteilten Fälle schließen sich an eine Reihe bereits veröffentlichter und vervollständigen in mancher Hinsicht das Bild, das die Beteiligung des Auges an dem Symptomenkomplex des X. $\mathbf{p}$. bietet in einer Weise, da $B$ es wohl verlohnt, an einer Zusammenfassung der bisher beschriebenen Fälle die Einzelheiten dieses Bildes näher zu erörtern. Eine tabellarische Zusammenstellung wird diese Aufgabe erleichtern. 
Rudolf Lederer: Die Beteiligung des Auges

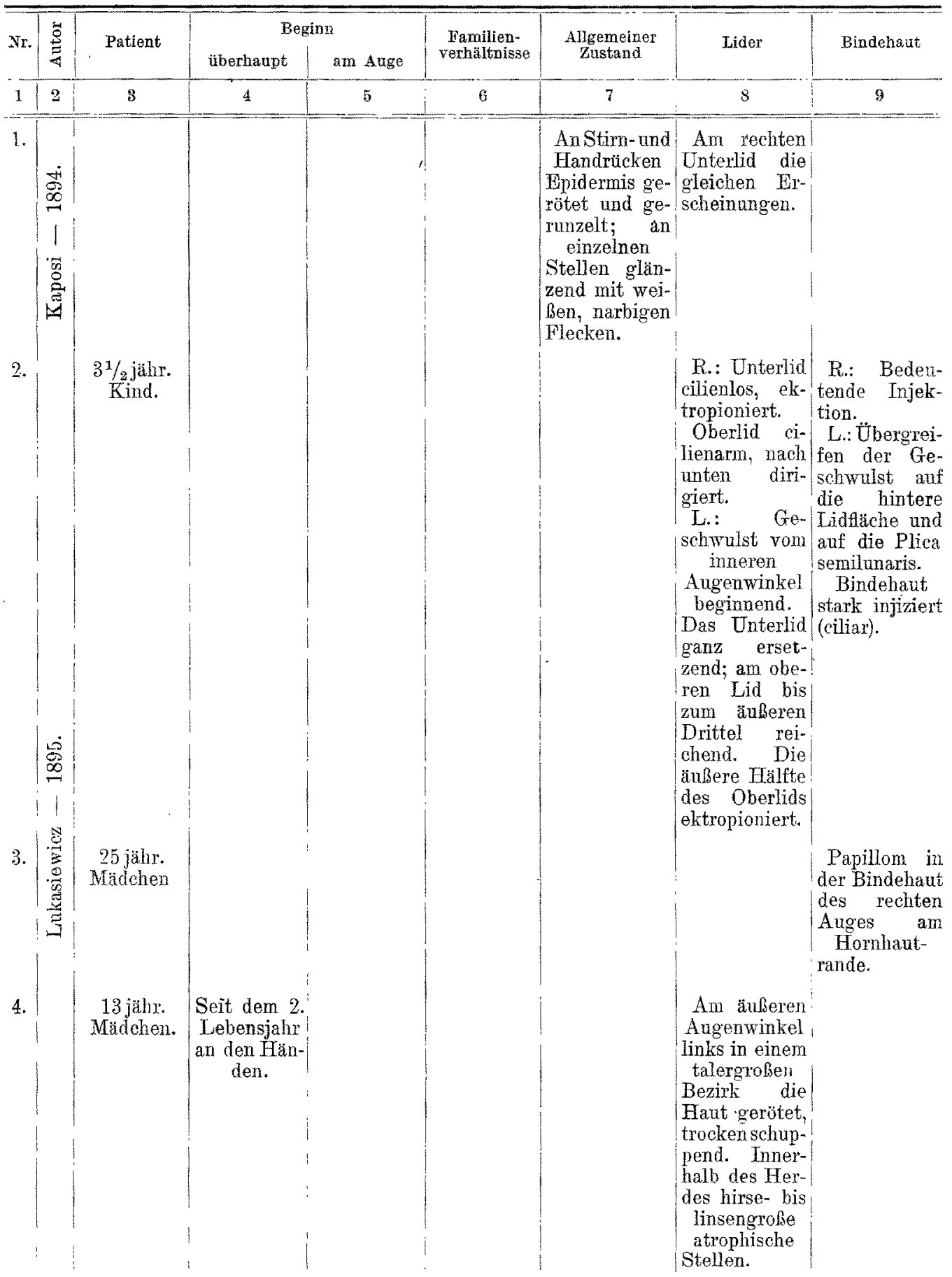


an dem Krankheitsbilde des Xeroderma pigmentosum.

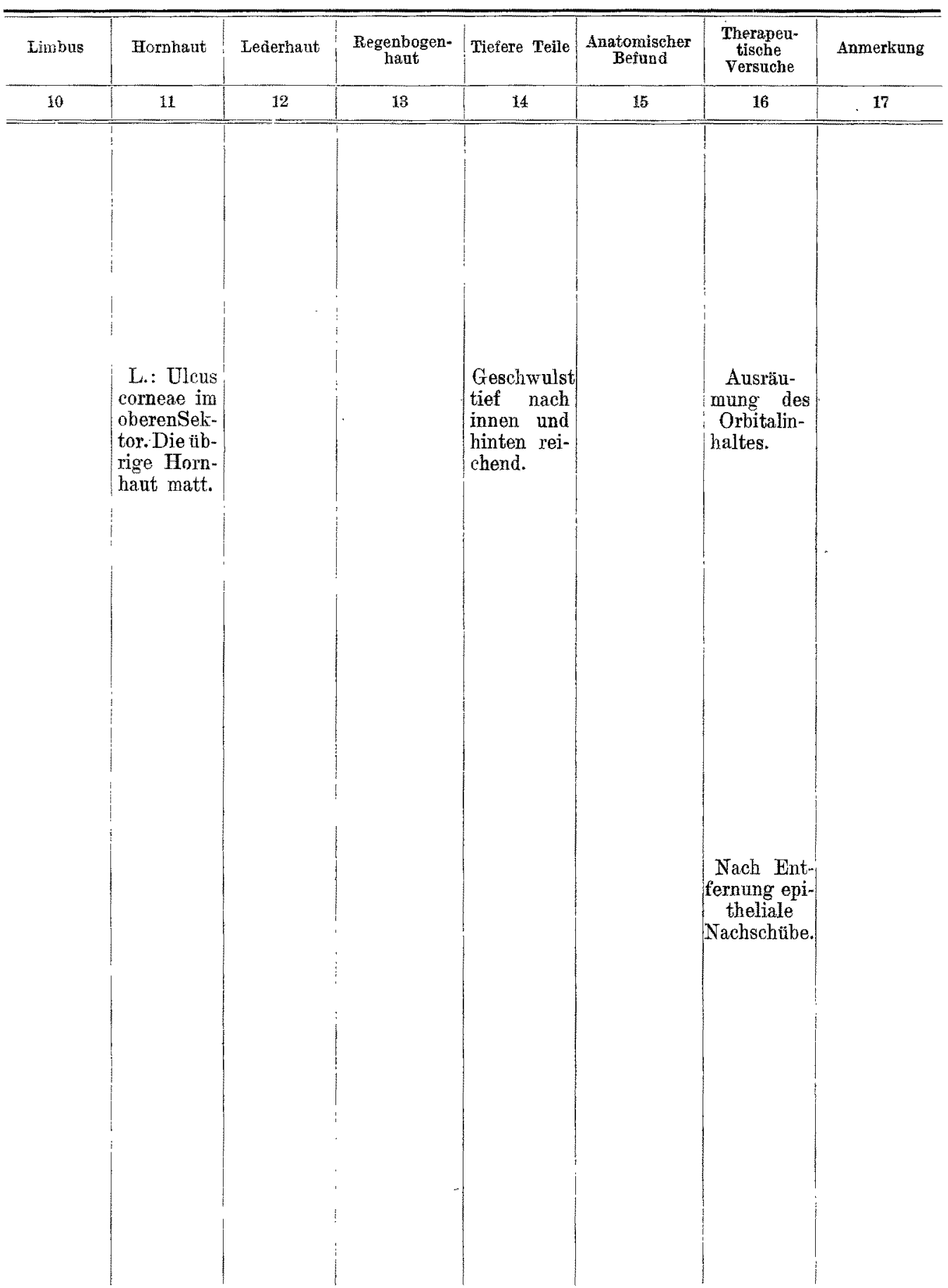




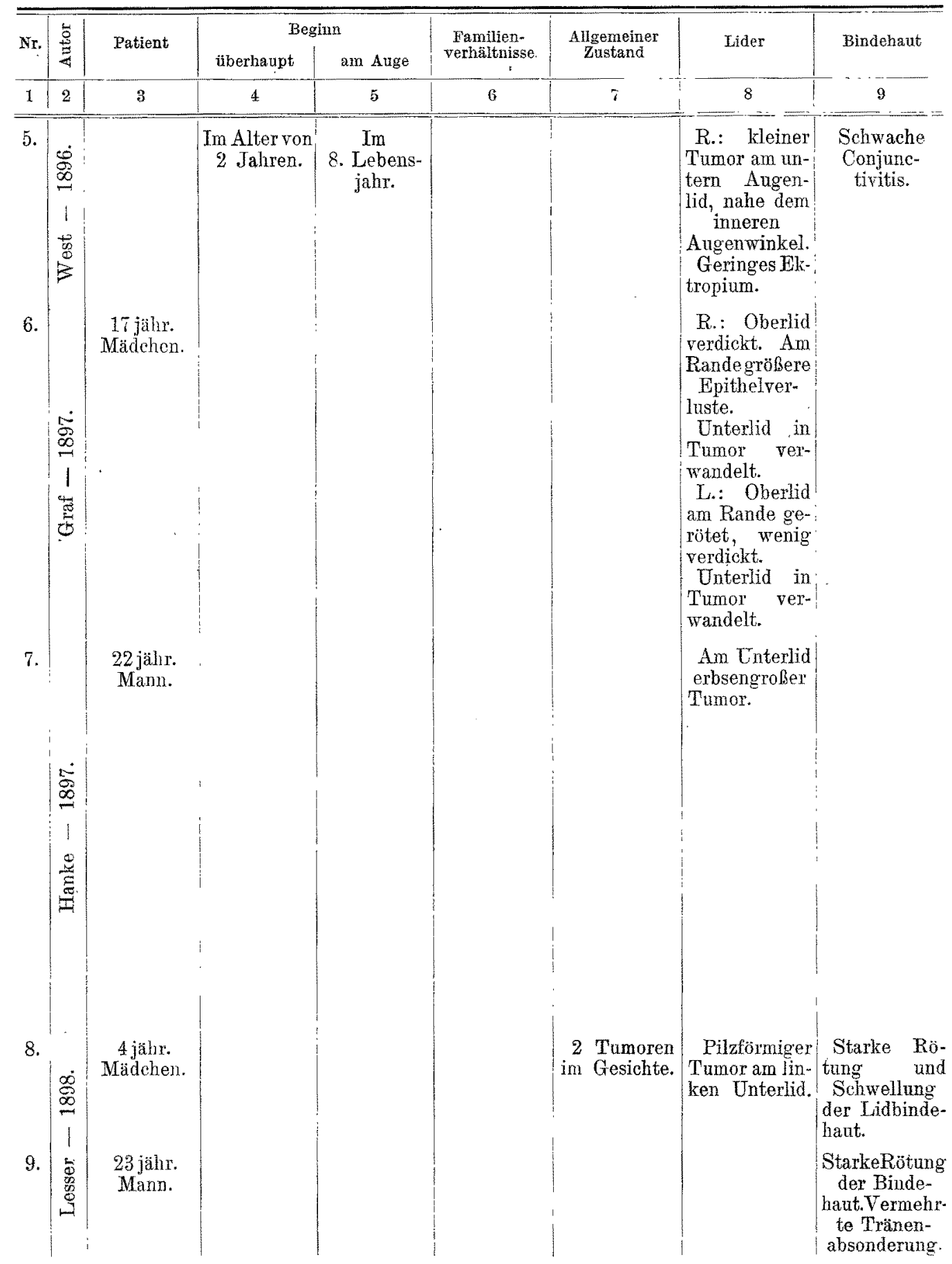


an dem Krankheitsbilde des Xeroderma pigmentosum.

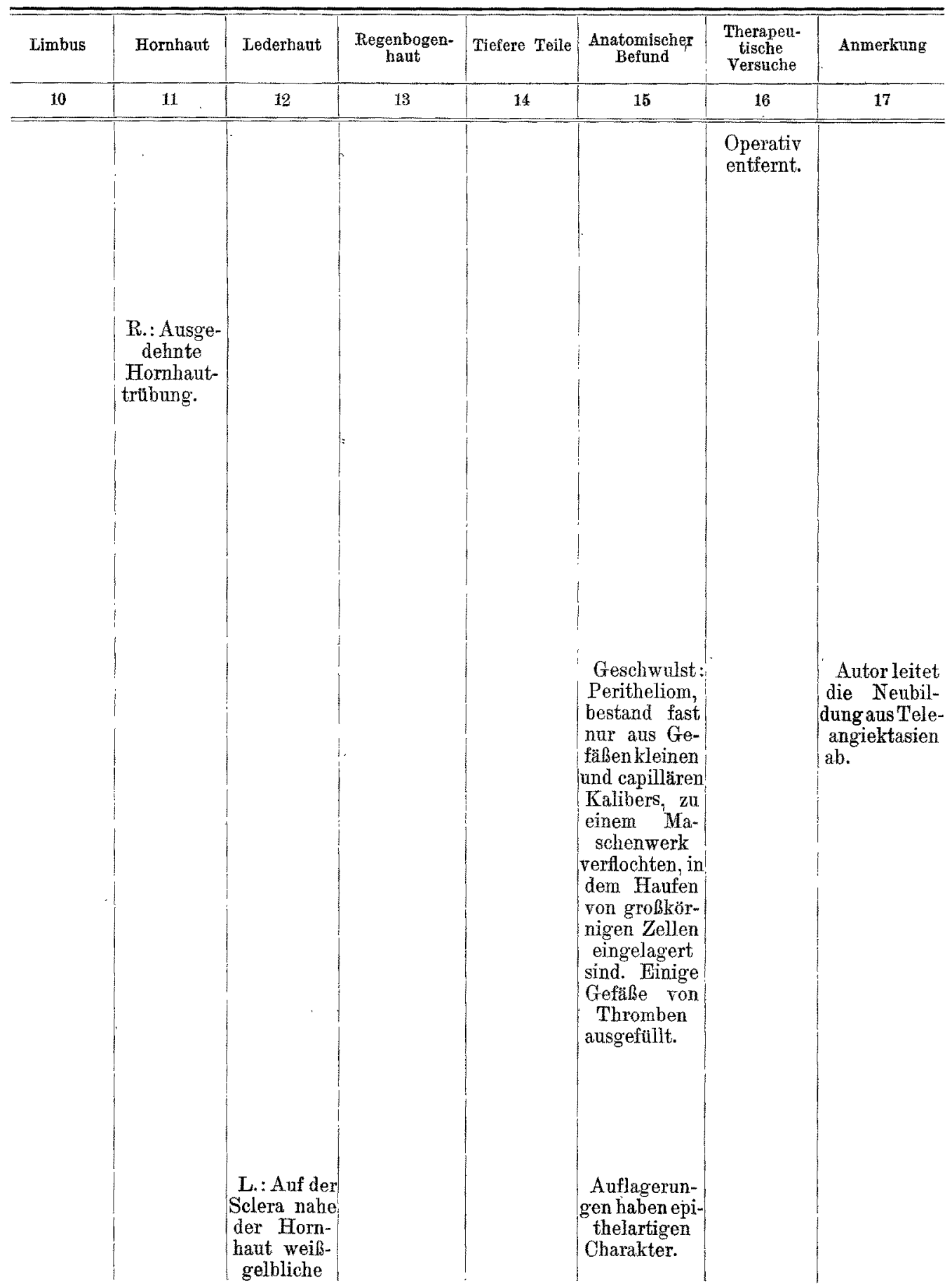




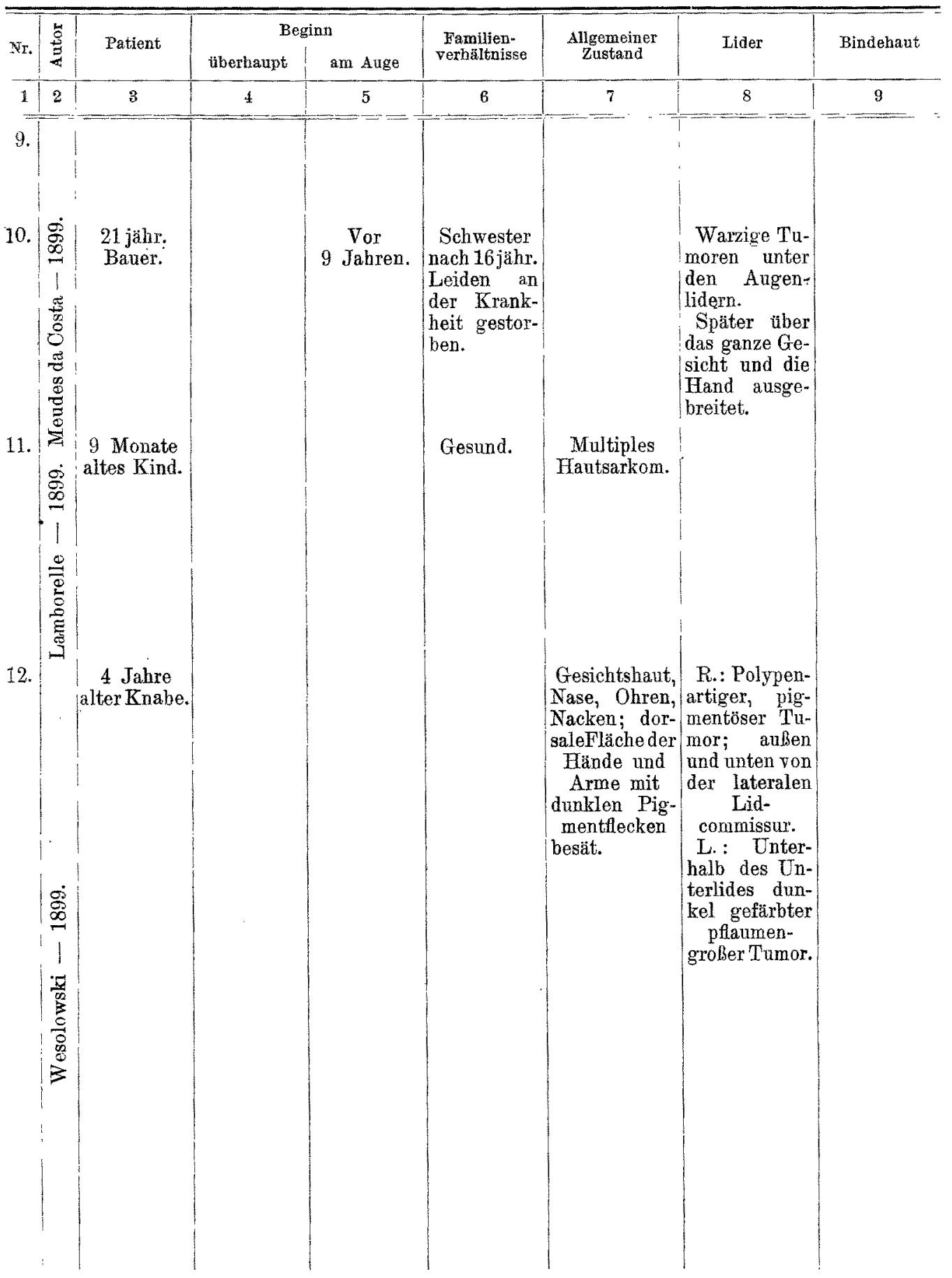


an dem Krankheitsbilde des Xeroderma pigmentosum.

\begin{tabular}{|c|c|c|c|c|c|c|c|}
\hline Limbus & Hornhaut & Lederhat & $\begin{array}{c}\text { Regenbogen- } \\
\text { hant }\end{array}$ & Tiefere Teile & $\begin{array}{l}\text { Anatomischer } \\
\text { Befund }\end{array}$ & $\begin{array}{l}\text { Therapeu- } \\
\text { tische } \\
\text { Versuche }\end{array}$ & Anmerkung \\
\hline 10 & 11 & 12 & 13 & 14 & 15 & 16 & 17 \\
\hline $\begin{array}{c}\text { Geschwnlst } \\
3 \mathrm{~mm} \text { auf die } \\
\text { Hornhaut } \\
\text { reichend,Re- } \\
\text { zidiv eines } \\
4 \text { Monate } \\
\text { früher ent- } \\
\text { fernten erb- } \\
\text { sengroßen } \\
\text { Trumors. }\end{array}$ & & $\begin{array}{l}\text { Wucherun- } \\
\text { gen mit un- } \\
\text { ebener Ober- } \\
\text { fläche. } \\
\text { Tumor der } \\
\text { Sclera, fuhrt } \\
\text { zu Astigma- } \\
\text { tismus mit } \\
\text { Herabset- } \\
\text { zung des } \\
\text { Sehvermö- } \\
\text { gens bis anf } \\
\text { Lichtschein. }\end{array}$ & & & $\begin{array}{l}\text { In der Haut: } \\
\text { Spindelzellen- } \\
\text { sarkom, in Fi- } \\
\text { brom uber- } \\
\text { gehend, mit } \\
\text { zerstrenten } \\
\text { melanotischen } \\
\text { Zellen. } \\
\\
\\
\text { Xeroderma- } \\
\text { flecke: Herd- } \\
\text { weises Auf- } \\
\text { treten abnorm } \\
\text { großen Pig- } \\
\text { mentgehaltes } \\
\text { in den Chro- } \\
\text { matophoren } \\
\text { der Haut. } \\
\text { Übergang } \\
\text { des Pigments } \\
\text { in die Epider- } \\
\text { mis, vorwie- } \\
\text { gend in die } \\
\text { Basalzellen } \\
\text { der Stachel- } \\
\text { schicht. Letz- } \\
\text { tere degene- } \\
\text { rieren unter } \\
\text { Schwund der } \\
\text { elastischen } \\
\text { Fasern. } \\
\text { Schließlich } \\
\text { liegt die Eppi- } \\
\text { dermis der } \\
\text { papillären } \\
\text { Lederhaut } \\
\text { glattan. Die }\end{array}$ & $\begin{array}{l}\text { Rezidiv } 7 \\
\text { Wochen } \\
\text { nach Ex- } \\
\text { stirpation } \\
\text { bemerkt. }\end{array}$ & \\
\hline
\end{tabular}




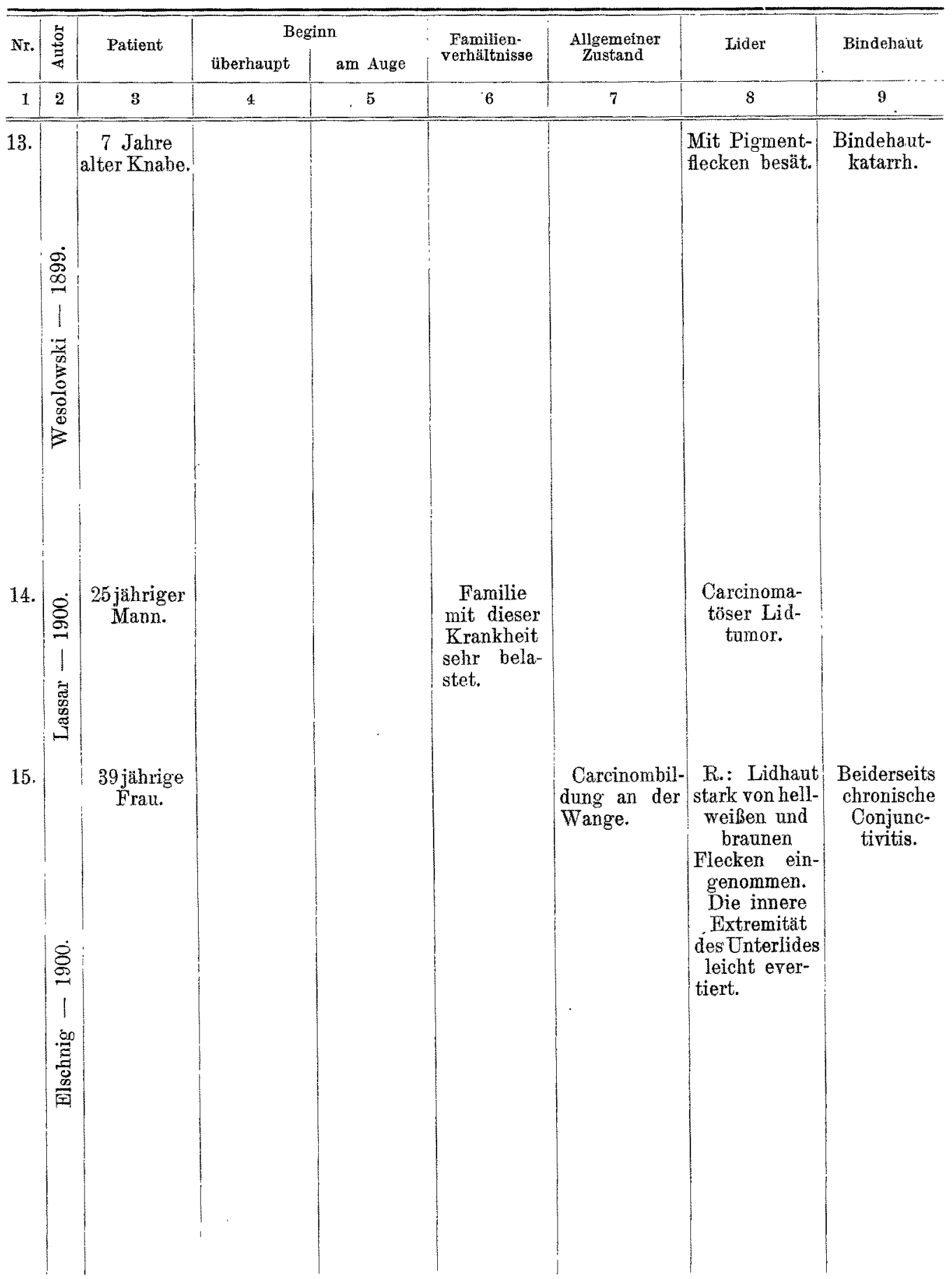


an dem Krankheitsbilde des Xeroderma pigmentosum.

\begin{tabular}{|c|c|c|c|c|c|c|c|}
\hline Limbus & Hornhaut & Lederhaut & $\begin{array}{c}\text { Regenbogen- } \\
\text { haut }\end{array}$ & Tiefere Teile & $\begin{array}{l}\text { Anatomischer } \\
\text { Befund }\end{array}$ & $\begin{array}{l}\text { Therapeu. } \\
\text { tische } \\
\text { Versuche }\end{array}$ & Anmerkung \\
\hline 10 & $\pi$ & 12 & 13 & 14 & 15 & 16 & 17 \\
\hline & \begin{tabular}{|} 
Am Horn- \\
hantrande \\
zarteNarben \\
mit GefäB- \\
neubildun- \\
gen (nach \\
Keratitis ek- \\
zematosa).
\end{tabular} & & $\begin{array}{l}\text { L.: Ciliarteil } \\
\text { hellgrauweiß } \\
\text { mit aufgesetz- } \\
\text { ten hanfliorn- } \\
\text { bis steck- } \\
\text { nadelkopf- } \\
\text { großen, dun- } \\
\text { kelbraun pig- } \\
\text { mentierten, } \\
\text { vorragenden } \\
\text { Flecken mit } \\
\text { samtartiger } \\
\text { Oberilähe. } \\
\text { Dazwischen } \\
\text { das Stroma } \\
\text { eingesunken, } \\
\text { die GefäBchen } \\
\text { von einem un- } \\
\text { pigmentierten } \\
\text { Gewebe ein- } \\
\text { gehüllt, an } \\
\text { einzelnen } \\
\text { Stellen spär- } \\
\text { licher. }\end{array}$ & & $\begin{array}{l}\text { oberfläch- } \\
\text { lichen Capil- } \\
\text { laren von An- } \\
\text { fang an ekta- } \\
\text { tisch. Wuche- } \\
\text { rung der Ge- } \\
\text { fäbe führt zur } \\
\text { Bildung von } \\
\text { Angiomen. } \\
\text { Wucherung } \\
\text { der Endothe- } \\
\text { lien zu Endo- } \\
\text { thelsarkom. } \\
\text { An der Bil- } \\
\text { dung von mela- } \\
\text { notischen Sar- } \\
\text { komen haben } \\
\text { die Chromato } \\
\text { phoren der } \\
\text { Haut Anteil. }\end{array}$ & & $\begin{array}{l} \\
\\
\text { Eigenartige } \\
\text { Atrophie und } \\
\text { Hypertrophie } \\
\text { der Pigment- } \\
\text { zellen und des } \\
\text { Bindegewebes } \\
\text { der Iris wie } \\
\text { in der Haut. } \\
\end{array}$ \\
\hline
\end{tabular}




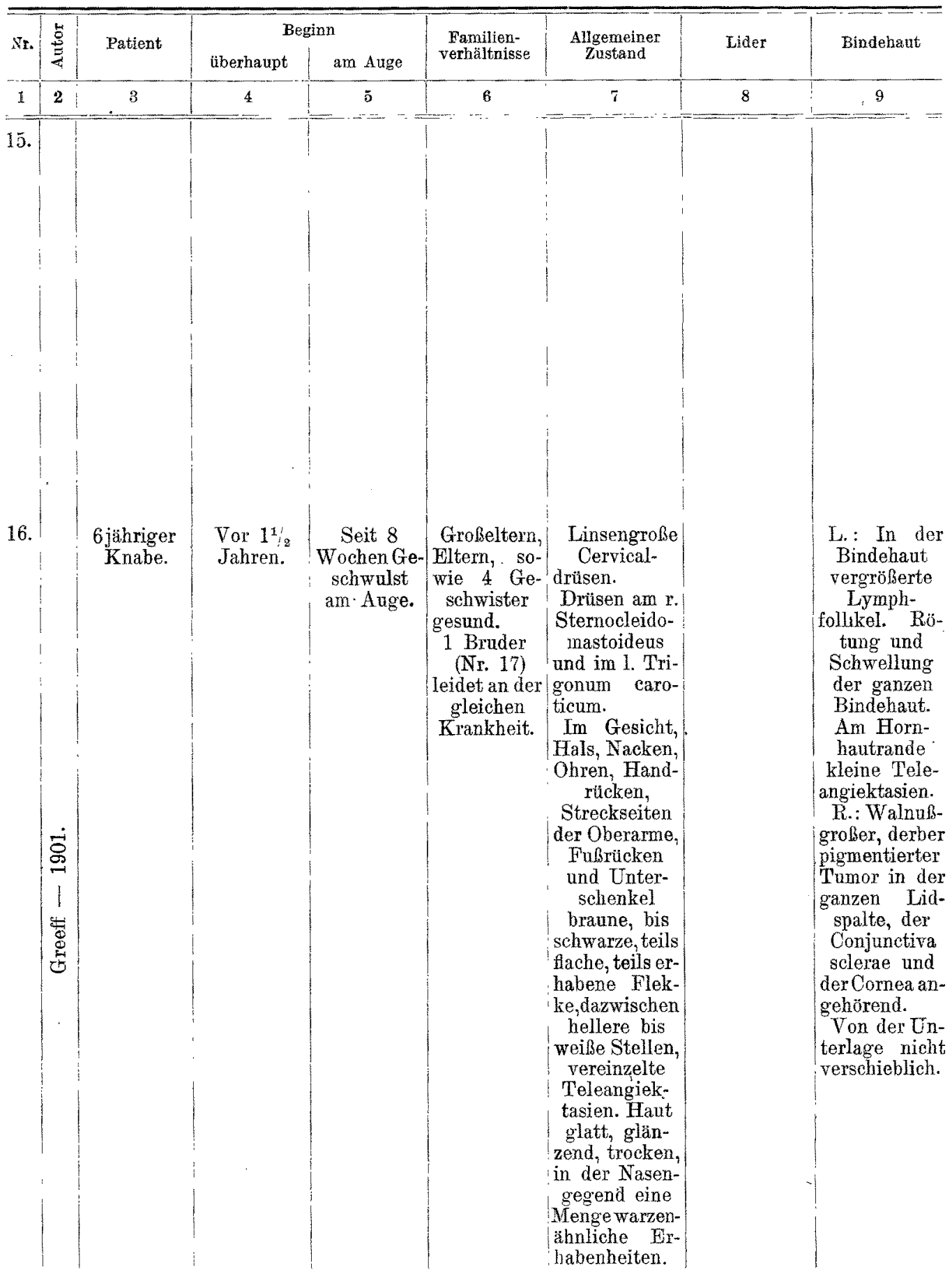


an dem Krankheitsbilde des Xeroderma pigmentosum.

\begin{tabular}{|c|c|c|c|c|c|c|c|}
\hline Limbus & Hornhant & Lederhaut & $\begin{array}{c}\text { Regenbogen- } \\
\text { haut }\end{array}$ & Tiefere Teile & $\begin{array}{l}\text { Anatomiseher } \\
\text { Befund }\end{array}$ & $\begin{array}{l}\text { Therapeu- } \\
\text { tische } \\
\text { Versuche }\end{array}$ & Anmerkung \\
\hline 10 & 11 & 12 & 13 & 14 & 15 & 16 & 17 \\
\hline & $\begin{array}{l}\text { Siehe unter } \\
\text { "Binde- } \\
\text { haut". } \\
\text { Der sicht- } \\
\text { bare Rest } \\
\text { der Horn- } \\
\text { haut leicht } \\
\text { getrubt. }\end{array}$ & $\begin{array}{l}\text { Siehe unter } \\
\text { Binde- } \\
\text { haut". }\end{array}$ & $\begin{array}{l}\text { R.: Der äu- } \\
\text { Bere, untere } \\
\text { Quadrant nor- } \\
\text { mal, brann ge- } \\
\text { farbt; sonst } \\
\text { wie links. } \\
\text { Die einzel- } \\
\text { nen Pigment- } \\
\text { fecke erschei- } \\
\text { nen kompak- } \\
\text { ter, dunkler } \\
\text { gefärbt, als die } \\
\text { nicht verän- } \\
\text { derten Iris- } \\
\text { teile. } \\
\text { Keine ent- } \\
\text { zundlichen Er- } \\
\text { scheinungen. }\end{array}$ & $\begin{array}{l}\text { (1n den Mus- } \\
\text { kelfasern } \\
\text { des M. rect } \\
\text { int. und im } \\
\text { Fettgewebe. } \\
\text { reicht fast } \\
\text { bis zum } \\
\text { Aequator } \\
\text { bulbi, endet } \\
\text { in }\end{array}$ & $\begin{array}{l}\text { Typisches } \\
\text { Schleimhaut- } \\
\text { carcinom bis } \\
\text { in die Horn- } \\
\text { haut ond Le- } \\
\text { derhaut und, } \\
\text { diese durch- } \\
\text { setzend, bis in } \\
\text { den Kammer- } \\
\text { winkel und in } \\
\text { die Aderhaut } \\
\text { reichend, of- } \\
\text { fenbar aufdem } \\
\text { Wege der ror- } \\
\text { deren Ciliar- } \\
\text { gefube. } \\
\text { Der Horn- } \\
\text { hauttrtbung } \\
\text { liegt Oddem zu-| } \\
\text { grunde. Prä- } \\
\text { cipitate, be- } \\
\text { stehend aus } \\
\text { Rundzellen } \\
\text { mitPigment- } \\
\text { körnchen, da- } \\
\text { zwischen Car- } \\
\text { cinomzellen. } \\
\text { Iris stark ge- } \\
\text { schwollen, mit } \\
\text { Rundzellen } \\
\text { durchsetzt, } \\
\text { das Gewebe } \\
\text { ungewöhnlich } \\
\text { pigmentreich. } \\
\text { Auch die }\end{array}$ & $\begin{array}{l}\text { Enuclea- } \\
\text { tion. } \\
\text { Kein Rezi- } \\
\text { div, kein } \\
\text { Fontschrei- } \\
\text { ten. } \\
\text { Schlafsucht. } \\
\text { Das andere } \\
\text { Auge durch } \\
\text { Eiterung zu- } \\
\text { grunde ge- } \\
\text { gangen. }\end{array}$ & \\
\hline
\end{tabular}




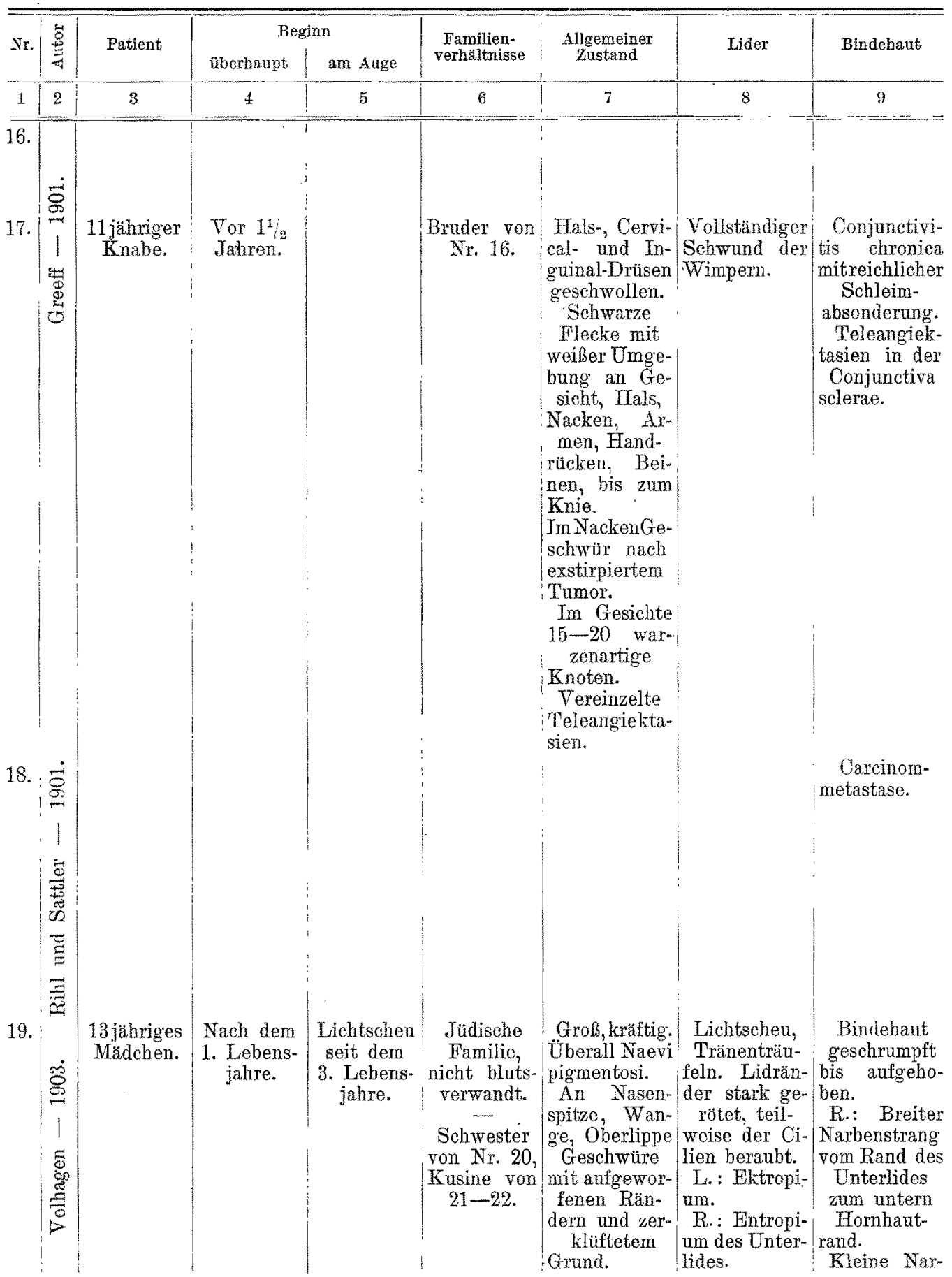


an dem Krankheitsbilde des Xeroderma pigmentosum.

\begin{tabular}{|c|c|c|c|c|c|c|c|}
\hline Limbus & Hornhaut & Lederhaut & $\begin{array}{c}\text { Regenbogen- } \\
\text { haut }\end{array}$ & Tiefere Teile & $\begin{array}{l}\text { Anatomischer } \\
\text { Befund }\end{array}$ & $\begin{array}{l}\text { Therapeu- } \\
\text { tische } \\
\text { Versuche }\end{array}$ & Anmerknng \\
\hline 10 & 11 & 12 & 18 & 11 & 15 & 16 & 17 \\
\hline & $\begin{array}{l}\text { R.: Innen } \\
\text { unten drei- } \\
\text { eckige Trü- } \\
\text { bung, vom } \\
\text { Limbns bis } \\
\text { fast zur } \\
\text { Mitte. } \\
\end{array}$ & $\begin{array}{l}\text { L.: Dunk- } \\
\text { lerPigment- } \\
\text { fleck in der } \\
\text { Selera. }\end{array}$ & & & $\begin{array}{l}\text { Hautknoten } \\
\text { geben das Bild } \\
\text { eines Carci- } \\
\text { noms. }\end{array}$ & & $\begin{array}{l}\text { Mit } 12 \text { Jah- } \\
\text { ren an Schlag- } \\
\text { anfällen ge- } \\
\text { storben nach } \\
\text { vorange- } \\
\text { gangener, zu- } \\
\text { nehmender } \\
\text { allgemeiner } \\
\text { Schwäche. }\end{array}$ \\
\hline $\begin{array}{l}\text { Siehe unter } \\
\text { Hornhant. }\end{array}$ & $\begin{array}{l}\text { Carcinom- } \\
\text { metastase } \\
\text { ausgehend } \\
\text { vonden Pa- } \\
\text { pillen des } \\
\text { Limbus. } \\
\\
\text { Von tief- } \\
\text { sitzenden } \\
\text { Flecken } \\
\text { durchsetzt. }\end{array}$ & & & 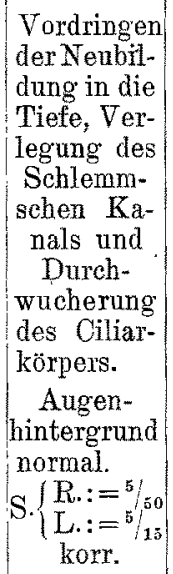 & & & \\
\hline
\end{tabular}




\begin{tabular}{|c|c|c|c|c|c|c|c|c|}
\hline \multirow{2}{*}{ Nr. } & \multirow{2}{*}{$\begin{array}{l}\ddot{D} \\
\stackrel{E}{Z}\end{array}$} & \multirow{2}{*}{ Patient } & \multicolumn{2}{|c|}{ Beginn } & \multirow{2}{*}{$\begin{array}{c}\text { Familien- } \\
\text { verhältnisse }\end{array}$} & \multirow{2}{*}{$\begin{array}{l}\text { Allgemeiner } \\
\text { Zustand }\end{array}$} & \multirow{2}{*}{ Lider } & \multirow{2}{*}{ Bindehaut } \\
\hline & & & tberhaupt & am suge & & & & \\
\hline 1 & 2 & 3 & 4 & 5 & 6 & 7 & 8 & 9 \\
\hline 19. & $\mid \begin{array}{c}\stackrel{8}{8} \\
\stackrel{2}{2} \\
1\end{array}$ & & & & & $\begin{array}{l}\text { Hyperkera- } \\
\text { tosen. } \\
\text { Die Haut des } \\
\text { Nasen- } \\
\text { ruickens, Joch- } \\
\text { bogens, Ober- } \\
\text { lippe und } \\
\text { Stimn weiß, } \\
\text { pergament- } \\
\text { artig, hart, } \\
\text { dünn, prall } \\
\text { gespannt. } \\
\text { Gesicht, } \\
\text { Ruickenfläche } \\
\text { der Hand und } \\
\text { Vorderarme } \\
\text { gelbbraun } \\
\text { pigmentiert, } \\
\text { mit rötlichen } \\
\text { Flecken. Ge- } \\
\text { fäßektasien. }\end{array}$ & & $\begin{array}{l}\text { benstreifen zu } \\
\text { Karunkel und } \\
\text { innerem Ran- } \\
\text { de der Horn- } \\
\text { haut. }\end{array}$ \\
\hline 20. & 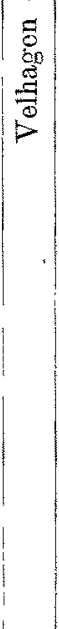 & $\begin{array}{c}7 \text { jähr. } \\
\text { Mädchen. }\end{array}$ & $\begin{array}{l}\text { im 3.Lebens- } \\
\text { jahre. }\end{array}$ & & $\begin{array}{c}\text { Schwester } \\
\text { von Nr. } 19 .\end{array}$ & \begin{tabular}{|} 
Klein, grazil. \\
Hant des Na- \\
senrïckens \\
und der Joch- \\
bögen perga- \\
mentartig ver- \\
ändert. \\
Gesicht und \\
Ohren stark \\
pigmentiert \\
mit warzigen \\
Knötchen und \\
Hornschup- \\
pen besetzt. \\
Onterarme \\
und Rücken- \\
Alizchen der \\
Hände mit \\
tiefbraunen \\
Flecken besät.
\end{tabular} & $\begin{array}{l}\text { An den Un- } \\
\text { terlidern und } \\
\text { inneren Lid- } \\
\text { winkeln ver- } \\
\text { narbte Ge Ge- } \\
\text { schwire. } \\
\text { Wimpern } \\
\text { zum Teile aus- } \\
\text { gefallen. } \\
\text { Unterlider } \\
\text { teilweise ek- } \\
\text { tropioniert. }\end{array}$ & $\begin{array}{l}\text { L.: Narben- } \\
\text { strang von der } \\
\text { Karunkel zur } \\
\text { Homhaut. } \\
\text { Bindehaut } \\
\text { byperämiseh. }\end{array}$ \\
\hline 21. & & $\begin{array}{l}12 \text { jähr. } \\
\text { Mädchen. }\end{array}$ & & & $\begin{array}{l}\text { Schwester } \\
\text { von Nr. 22. } \\
\text { Schwester } \\
\text { an Xerod. } \\
\text { pigm.gestor- } \\
\text { ben. }\end{array}$ & $\begin{array}{c}\text { Gut entwik- } \\
\text { kelt. Hant } \\
\text { des Gesichtes, } \\
\text { Hals, der } \\
\text { Hand, des } \\
\text { Unterarmes } \\
\text { mulattenartig } \\
\text { mit geringer } \\
\text { Warzenbil- } \\
\text { dung und Epi- } \\
\text { dermisab- }\end{array}$ & & $\begin{array}{l}\text { Narben- } \\
\text { strang beider- } \\
\text { seits zwischen } \\
\text { Karunkel und } \\
\text { inneremHorn- } \\
\text { hautrand. }\end{array}$ \\
\hline
\end{tabular}


an dem Krankheitsbilde des Xeroderma pigmentosum.

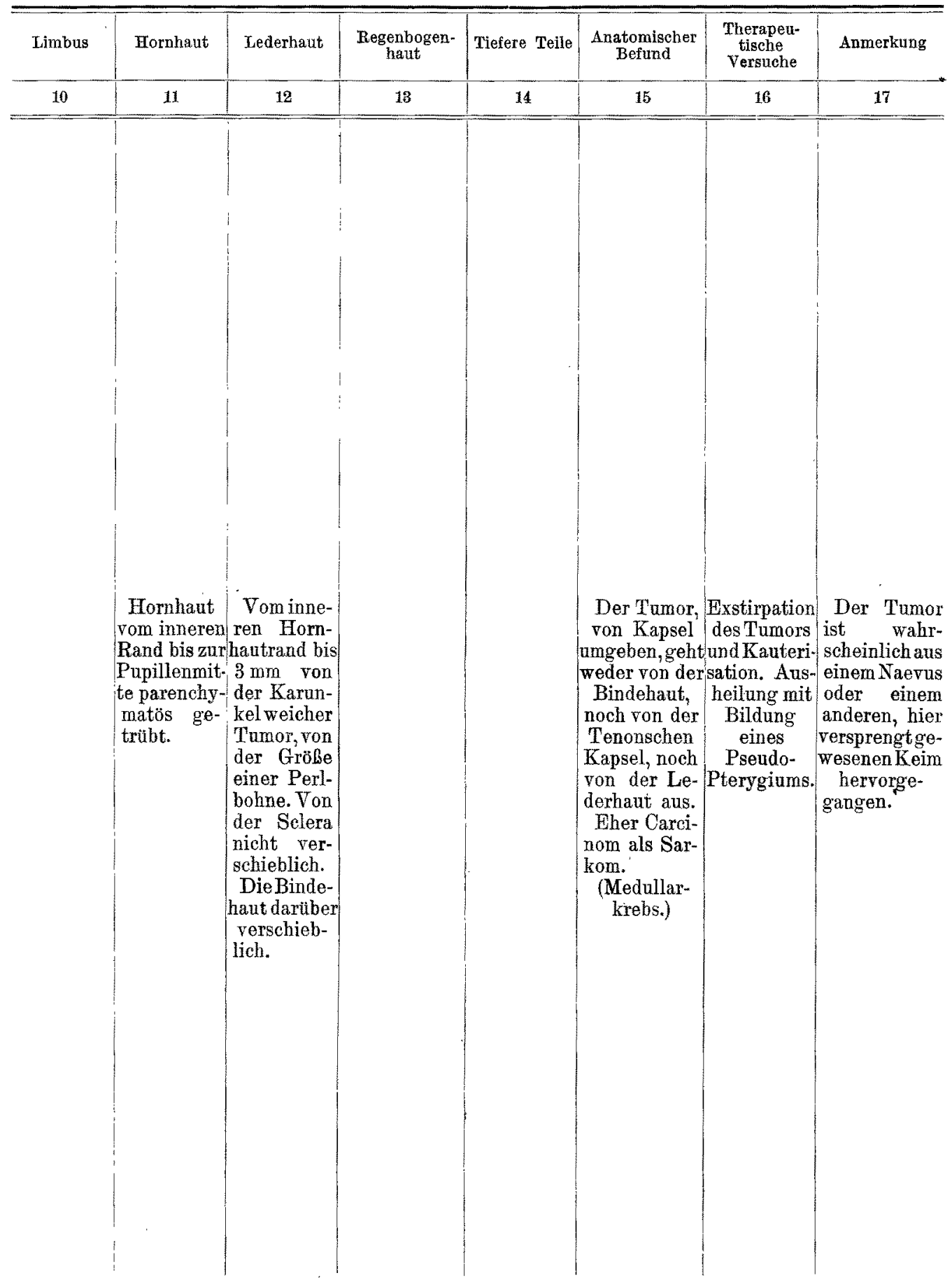

v. Graefes Archiv fur Ophthalmologie. Bd. 100. 


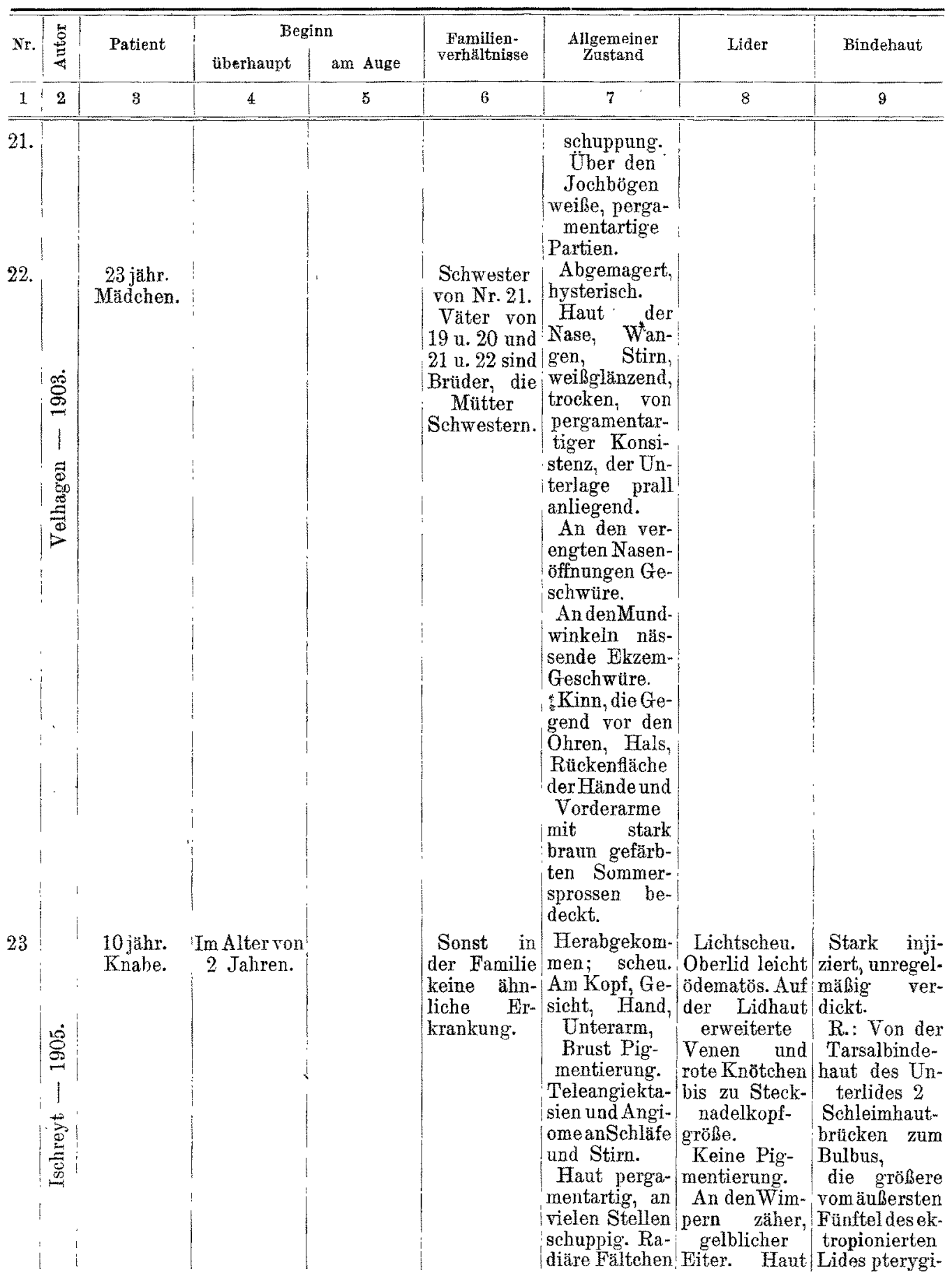


an dem Krankheitsbilde des Xeroderma pigmentosum.

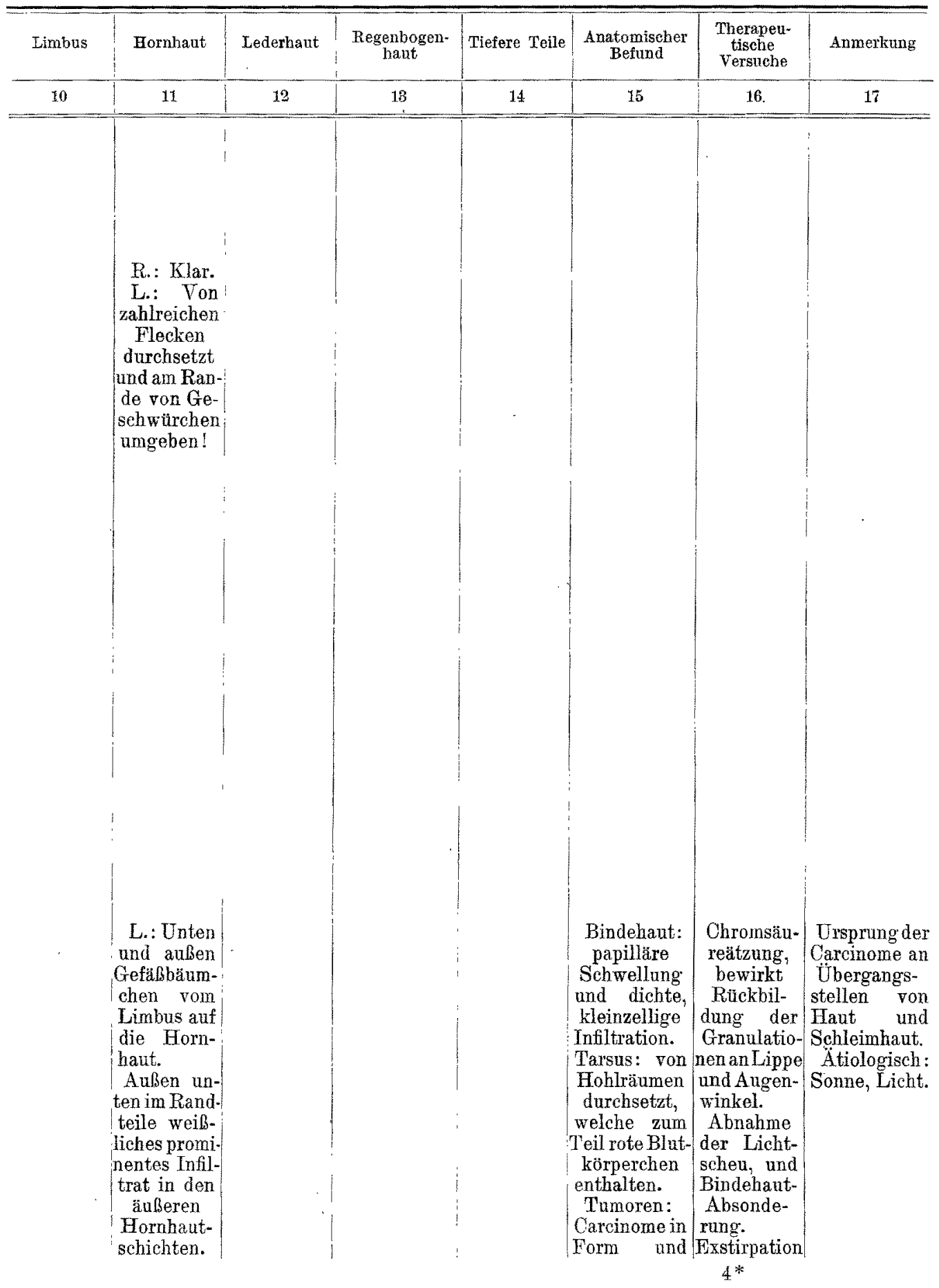




\begin{tabular}{|c|c|c|c|c|c|c|c|c|}
\hline \multirow{2}{*}{ Nr. } & \multirow{2}{*}{ 苞 } & \multirow{2}{*}{ Patient } & \multicolumn{2}{|c|}{ Beginn } & \multirow{3}{*}{$\begin{array}{c}\begin{array}{c}\text { Familien- } \\
\text { verhältnisse }\end{array} \\
6 \\
6\end{array}$} & \multirow{2}{*}{$\begin{array}{l}\text { Allgemeiner } \\
\text { Zustand }\end{array}$} & \multirow{2}{*}{ Lider } & \multirow{2}{*}{ Bindehaut } \\
\hline & & & ¿iberhaupt & am Auge & & & & \\
\hline 1 & 2 & 3 & 4 & 5 & & 7 & 8 & 9 \\
\hline 23. & 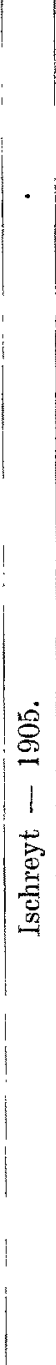 & & & & & $\begin{array}{l}\text { um Nase, } \\
\text { Mund und } \\
\text { Augenöff- } \\
\text { nungen. } \\
\text { In der Mitte } \\
\text { derUnterlippe } \\
\text { leicht bluten- } \\
\text { de, erbsen- } \\
\text { große Ge- } \\
\text { schwulst mit } \\
\text { geschwüriger } \\
\text { Oberfläche.Im } \\
\text { Gesicht viel- } \\
\text { fach Warzen. } \\
\text { Im veitern } \\
\text { Verlaufe 2röt- } \\
\text { lichweiße Er- } \\
\text { habenheiten } \\
\text { in der rechten } \\
\text { Hälfte der } \\
\text { Unterlippe. } \\
\text { Tiefe Ulce- } \\
\text { ration und } \\
\text { wulstartige } \\
\text { Verdickung } \\
\text { am rechten } \\
\text { Nasenflügel. }\end{array}$ & $\begin{array}{l}\text { der Unterlider } \\
\text { geschrumpft. } \\
\text { Narben-Ek- } \\
\text { tropium. Lid- } \\
\text { kanten ver- } \\
\text { strichen. Wim- } \\
\text { pern fast voll- } \\
\text { ständig } \\
\text { fehlend. Die } \\
\text { untem Trä- } \\
\text { nenpunkte ek- } \\
\text { tropioniert } \\
\text { und geschwol- } \\
\text { len. } \\
\text { Rechtsan der } \\
\text { innern Lid- } \\
\text { kommissur } \\
\text { erbsengroße } \\
\text { Granulation } \\
\text { mit schwarzen } \\
\text { Borsten, dar- } \\
\text { unter rahmi- } \\
\text { ger Eiter. } \\
\text { Im weiteren } \\
\text { Verlaufe tre- } \\
\text { ten links am } \\
\text { Unterlid } \\
\text { derbe Verdik- } \\
\text { kung mit ge- } \\
\text { schwürig zer- } \\
\text { klufteter } \\
\text { Oberfäche, } \\
\text { am Oberlid } \\
\text { warzenartige } \\
\text { Erhebungen, } \\
\text { ulceröser } \\
\text { Zerfall und } \\
\text { Tumorbildung } \\
\text { auf. } \\
\text { R.: Kugel- } \\
\text { förmige Ge- } \\
\text { schwulst im } \\
\text { inneren } \\
\text { Angenwinkel. }\end{array}$ & $\begin{array}{l}\text { umartig zum } \\
\text { äuleren, unte- } \\
\text { ren Hornhaut- } \\
\text { rand. } \\
\text { Im weiteren } \\
\text { Verlaufe star- } \\
\text { kere Schrump- } \\
\text { fung der Uber- } \\
\text { gangsfalte. }\end{array}$ \\
\hline 24 . & & $\begin{array}{l}13 \text { jähr. } \\
\text { Knabe. }\end{array}$ & $\begin{array}{c}\text { Im Altervon } \\
2 \text { Jahren. }\end{array}$ & $\begin{array}{c}\text { Seit } \\
\text { 3/4 Jahren } \\
\text { tränen die } \\
\text { Augen. Das } \\
\text { eine wird } \\
\text { trüber. }\end{array}$ & $\begin{array}{l}\text { Die Eltern } \\
\text { sind Ge- } \\
\text { schwister- } \\
\text { kinder. }\end{array}$ & $\begin{array}{l}\text { Schwäch- } \\
\text { licher Knabe; } \\
\text { an den Unter- } \\
\text { schenkeln } \\
\text { sommerspros- } \\
\text { senartige } \\
\text { Flecken. Ge- } \\
\text { sicht, Hals, } \\
\text { Unterarm, }\end{array}$ & $\begin{array}{l}\text { Lidhaut pig- } \\
\text { mentiert. An } \\
\text { beiden Ober- } \\
\text { lidern je ein } \\
\text { rötliches, breit } \\
\text { aufsitzendes } \\
\text { Geschwulst- } \\
\text { chen. } \\
\text { Unterlider ek- }\end{array}$ & $\begin{array}{l}\text { Diffus inji- } \\
\text { ziert. Fleisch } \\
\text { rot, keine Pig- } \\
\text { mentflecken. } \\
\text { Augapfel-Bin- } \\
\text { dehaut inji- } \\
\text { zert. Augen } \\
\text { sehr licht- } \\
\text { scheu. }\end{array}$ \\
\hline
\end{tabular}


an dem Krankheitsbilde des Xeroderma pigmentosum.

\begin{tabular}{|c|c|c|c|c|c|c|c|}
\hline Limbus & Hornhaut & Lederhaut & $\begin{array}{c}\text { Regenbogen- } \\
\text { haut }\end{array}$ & Tiefere Teile & $\begin{array}{l}\text { Anatomischer } \\
\text { Befund }\end{array}$ & $\begin{array}{l}\text { Therapeu- } \\
\text { tische } \\
\text { versuche }\end{array}$ & Anmerkung \\
\hline 10 & 11 & 12 & 13 & 14 & 15 & 16 & 17 \\
\hline & \begin{tabular}{|l} 
R.: Ähnliche \\
Gefäßnen- \\
bildung itn \\
Randteile \\
der Horn- \\
haut. Zarte \\
weißiche \\
Trübungen \\
in der unte- \\
ren Hälfte. \\
Außen un- \\
ten,anschlie \\
Bend an die \\
pterygium \\
artige Bi \\
dung, ein \\
weißerFleck \\
wie links. \\
In einem \\
späterenSta- \\
dium Horn- \\
hauttri- \\
bung: \\
L.: Gegen \\
die Mitte \\
fortgeschrit- \\
ten. \\
R.: Die \\
Hornhaut in \\
der unteren \\
Hälfte von \\
feischigem \\
pannusarti- \\
gem Gewebe \\
bedeckt. \\
Nach Opera- \\
tion: \\
L.: Vascu- \\
larisirtes \\
Leukom. \\
R.: Dichte \\
pannusarti- \\
ge Trübung. \\
R.: Nor- \\
mal. \\
L.: Außen, \\
innen und \\
unten weit- \\
reichende \\
Pannusge- \\
fäße mit dif- \\
fuser ober-
\end{tabular} & & Normal. & Normal. & $\begin{array}{l}\text { Lagerung der } \\
\text { Zellen Sarko- } \\
\text { men ähnlich. }\end{array}$ & $\begin{array}{l}\text { des Lidtu- } \\
\text { mor links } \\
\text { und des Tum } \\
\text { mors im } \\
\text { inneren } \\
\text { Augenwin- } \\
\text { kels rechts. } \\
\text { Abtragung } \\
\text { des rechten } \\
\text { Nasenfiü- } \\
\text { gels mit } \\
\text { Plastik. }\end{array}$ & \\
\hline
\end{tabular}




\begin{tabular}{|c|c|c|c|c|c|c|c|c|}
\hline \multirow{2}{*}{ Nr. } & \multirow{2}{*}{ 菺 } & \multirow{2}{*}{ Patient } & \multicolumn{2}{|c|}{ Beginn } & \multirow{2}{*}{$\begin{array}{c}\text { Familien- } \\
\text { verhăltnisse }\end{array}$} & \multirow{2}{*}{$\begin{array}{l}\text { Allgemeiner } \\
\text { Zustand }\end{array}$} & \multirow{2}{*}{ Lider } & \multirow{2}{*}{ Bindehaut } \\
\hline & & & aberhaupt & am Auge & & & & \\
\hline 1 & 2 & 8 & 4 & 5 & 6 & 7 & 8 & 9 \\
\hline 24. & 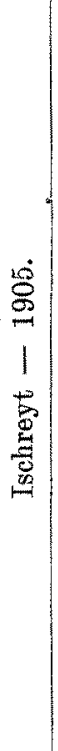 & . & & & & $\begin{array}{l}\text { Handrücken } \\
\text { mit großen } \\
\text { dunkelbrau- } \\
\text { nen Flecken } \\
\text { bedeckt. } \\
\text { Haut um } \\
\text { Augen, Nase, } \\
\text { Mund, an den } \\
\text { Beinen, glatt } \\
\text { gespannt. } \\
\text { Om die Ge- } \\
\text { sichtsöffnun- } \\
\text { gen feine ra- } \\
\text { diäre Haut- } \\
\text { narben. } \\
\text { Teleangiek- } \\
\text { tasien in der } \\
\text { erkrankten } \\
\text { Haut, außeran } \\
\text { Händen und } \\
\text { Hals. } \\
\text { Auf derStirn } \\
\text { keine Angi- } \\
\text { ome. }\end{array}$ & $\begin{array}{l}\text { tropioniert; } \\
\text { Lidränder ge- } \\
\text { schwollen, } \\
\text { Kanten ver- } \\
\text { strichen: } \\
\text { Madarosis. } \\
\text { In der Ge- } \\
\text { gend des lin- } \\
\text { ken unteren } \\
\text { Tränenpunk- } \\
\text { tes } 3 \text { mm gro- } \\
\text { Bes Angiom; } \\
\text { rechts auf dem } \\
\text { Lidrand flache } \\
\text { weiße Erha- } \\
\text { benheiten. }\end{array}$ & \\
\hline $\begin{array}{l}25 \\
\text { bis } \\
26 .\end{array}$ & 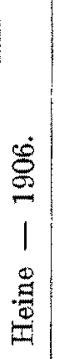 & 2 Fälle. & & & & $\begin{array}{l}\text { Stadium der } \\
\text { Pigmentie- } \\
\text { rung und glat- } \\
\text { ten Atrophie } \\
\text { der Haut. }\end{array}$ & $\begin{array}{l}\text { Verruca des } \\
\text { Oberlides. } \\
\text { Madarosis. }\end{array}$ & $\begin{array}{l}\text { Reichlich } \\
\text { vascularisier- } \\
\text { te Bindehaut- } \\
\text { falte rom Lid- } \\
\text { rand zur ät- } \\
\text { Bern nntern } \\
\text { Hornhautpar- } \\
\text { tie, diese } 1 / 2 \\
\text { bis } 1 \text { mm be- } \\
\text { deckend. }\end{array}$ \\
\hline 27. & 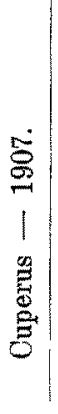 & $\begin{array}{l}\text { 10jähriges } \\
\text { Mädchen. }\end{array}$ & $\begin{array}{c}\text { Im Alter } \\
\text { von 3-4 } \\
\text { Jahren. }\end{array}$ & & $\begin{array}{l}\text { In der Fa- } \\
\text { milie keine } \\
\text { ähnliche Er- } \\
\text { krankung. } \\
\text { Eltern } \\
\text { nicht bluts- } \\
\text { verwandt. }\end{array}$ & $\begin{array}{l}\text { Sehr abge- } \\
\text { magert, zart, } \\
\text { schwacher } \\
\text { Puls, wenig } \\
\text { Appetit. } \\
\text { Haut an } \\
\text { Handrücken, } \\
\text { Gesicht, Hals, } \\
\text { Nacken atro- } \\
\text { phisch, glatt } \\
\text { gespannt, ab- } \\
\text { sehilfernd. } \\
\text { Reich an Pig- }\end{array}$ & $\begin{array}{l}\text { Rechts rom } \\
\text { Oberlid und } \\
\text { oberen Orbi- } \\
\text { talrand aus- } \\
\text { gehende Ge- } \\
\text { schwulst } \\
12 \times 9 \times 3 \text { cm } \\
\text { groß, fast die } \\
\text { ganze rechte } \\
\text { Gesiehtshalf- } \\
\text { te bedeckend, } \\
\text { überlagerud. } \\
\text { Das Oberlid }\end{array}$ & Gesehwollen. \\
\hline
\end{tabular}


an dem Krankheitsbilde des Xeroderma pigmentosum.

\begin{tabular}{|c|c|c|c|c|c|c|c|}
\hline Limbus & Hornhaut & Lederhaut & $\underset{\substack{\text { Regenbogen- } \\
\text { haut }}}{ }$ & Tiefere Teile & $\begin{array}{c}\text { Anatomigcher } \\
\text { Befund }\end{array}$ & $\begin{array}{l}\text { Therapeu- } \\
\text { tische } \\
\text { Versuche }\end{array}$ & Anmerkung \\
\hline 10 & 11 & 12 & 18 & 14 & 15 & 16 & 17 \\
\hline & $\begin{array}{l}\text { flächlicher } \\
\text { Trubung. }\end{array}$ & & & \begin{tabular}{|l|} 
\\
Periost des \\
Orbitalran- \\
des verdickt. \\
Das peri- \\
ostale Ge- \\
webe infil- \\
triert.
\end{tabular} & $\begin{array}{l}\text { Epitheliali- } \\
\text { sierte Binde- } \\
\text { hautfalte mit } \\
\text { mäbiger Ver- } \\
\text { mehrung der } \\
\text { elastischen } \\
\text { Elemente im } \\
\text { teils lockeren } \\
\text { teils derberen } \\
\text { Bindegewebe. } \\
\text { InderVerruca } \\
\text { außer elasti- } \\
\text { schen Fasern } \\
\text { nichts Beson- } \\
\text { deres. } \\
\text { Carcinom mit } \\
\text { sehr unregel- } \\
\text { mäßigen, au- } \\
\text { Berordentlich } \\
\text { großen und } \\
\text { sehr kleinen } \\
\text { Zellformen. }\end{array}$ & $\begin{array}{l}\text { Excision des } \\
\text { pterygium- } \\
\text { artigen } \\
\text { Symblepha- } \\
\text { ron. Abtra- } \\
\text { gung der } \\
\text { Warze. } \\
\\
\\
\text { Exstirpa- } \\
\text { tion. Nach4 } \\
\text { Wochen Re- } \\
\text { zidiv. }\end{array}$ & $\begin{array}{l} \\
\\
\\
\\
\\
\\
\\
\\
\\
\\
\text { Der nasale } \\
\text { Bereich und } \\
\text { der temporale } \\
\text { untere Qua- } \\
\text { drant: Prädi- } \\
\text { lektionstellen. } \\
\text { Primäre Lo- } \\
\text { kalisation an } \\
\text { den dem Lich- } \\
\text { te besonders } \\
\text { ausgesetzten } \\
\text { Stellen. } \\
\text { Strahlen. } \\
\text { Carcinom } \\
\text { entsteht in ei- }\end{array}$ \\
\hline
\end{tabular}




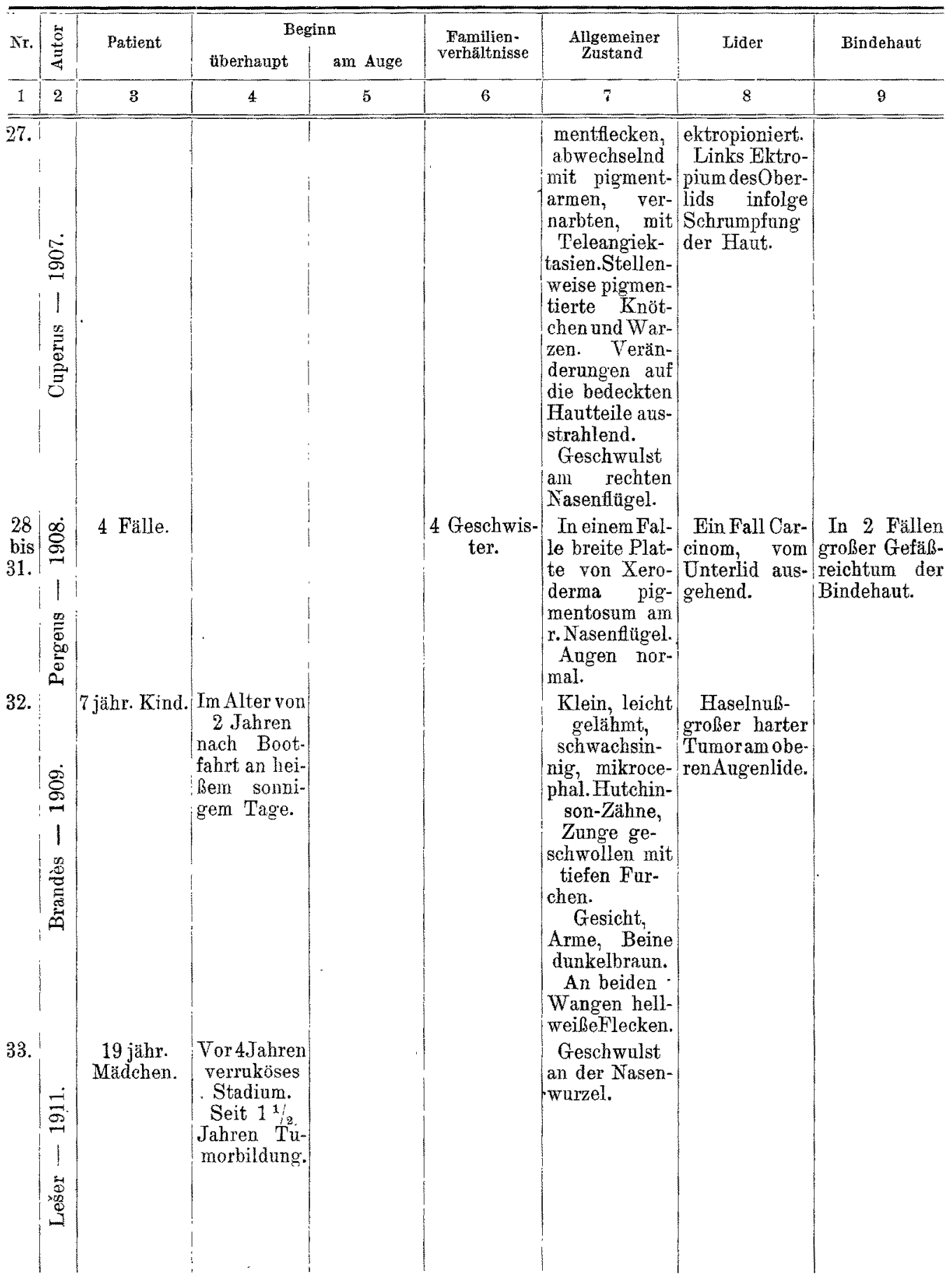


an dem Krankheitsbilde des Xeroderma pigmentosum.

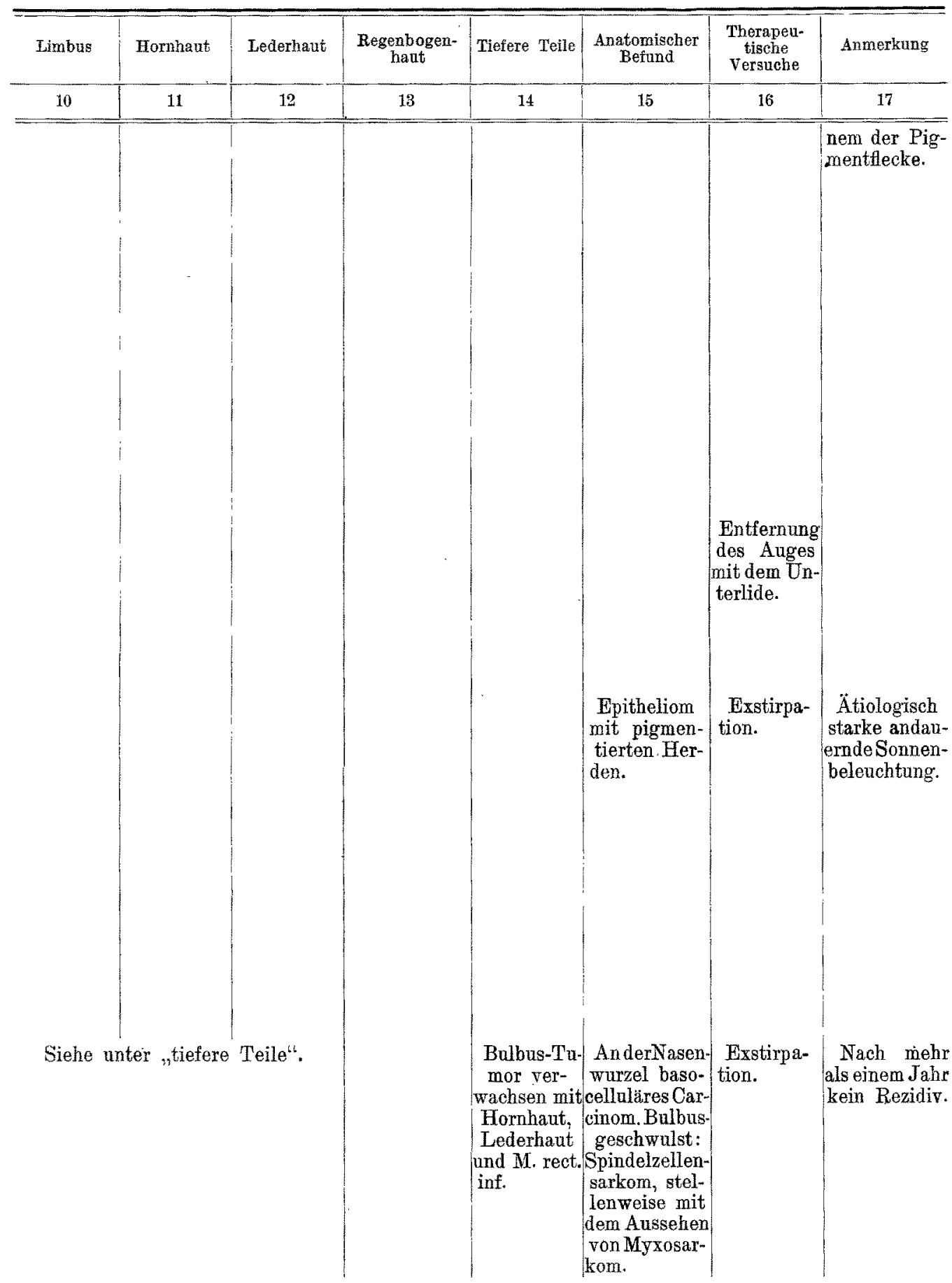




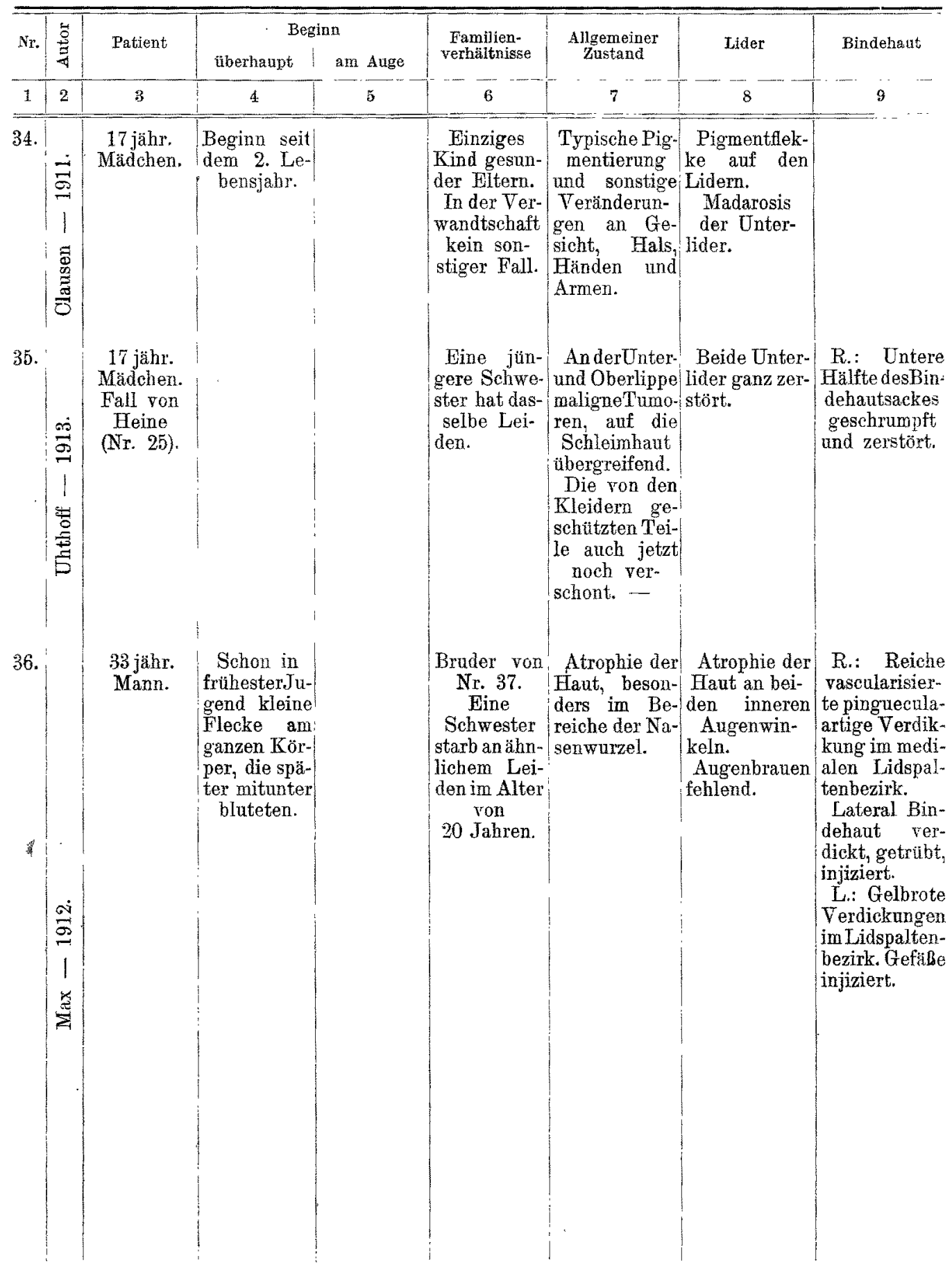


an dem Krankheitsbilde des Xeroderma pigmentosum.

\begin{tabular}{|c|c|c|c|c|c|c|c|}
\hline Limbus & Hornhat & Lederhaut & $\begin{array}{c}\text { Regenbogen } \\
\text { haut }\end{array}$ & Tiefere Teile & $\begin{array}{l}\text { Anatomisoher } \\
\text { Befund }\end{array}$ & $\begin{array}{l}\text { Therapeu* } \\
\text { tische } \\
\text { versuche }\end{array}$ & Anmerkung \\
\hline 10 & $11^{\circ}$ & 12 & 13 & 14 & 10 & 16 & 17 \\
\hline & 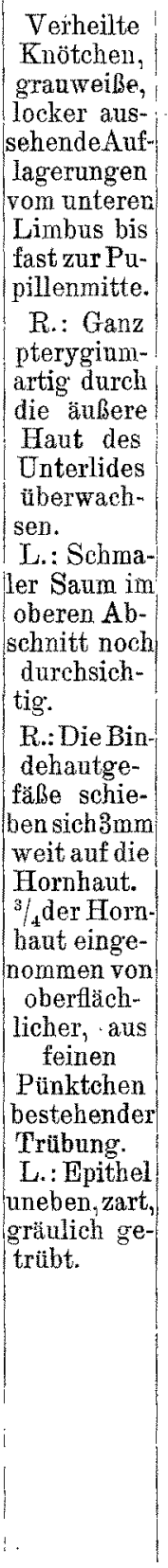 & & 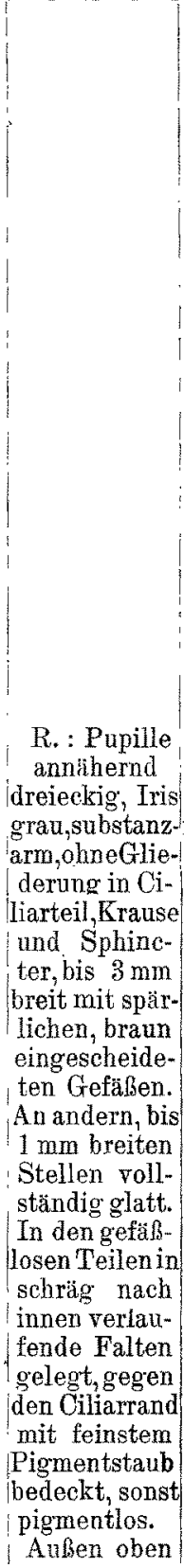 & $\begin{array}{l}\text { (1) P.breite } \\
\text { Pigmentie- } \\
\text { s.: An- } \\
\text { sung. } \\
\text { an die P. } \\
\text { naevusartige } \\
\text { 1/ Pund }\end{array}$ & $\begin{array}{l}\text { Verdicktes, } \\
\text { auf die Horn- } \\
\text { hant vorge- } \\
\text { schobenes } \\
\text { Conjunctival- } \\
\text { gewebe ohne } \\
\text { carcinomatöse } \\
\text { Entartung. }\end{array}$ & $\begin{array}{l}\text { Abtragung } \\
\text { der Auflage- } \\
\text { rumgen. }\end{array}$ & \\
\hline
\end{tabular}


Rudolf Lederer: Die Beteiligung des Auges

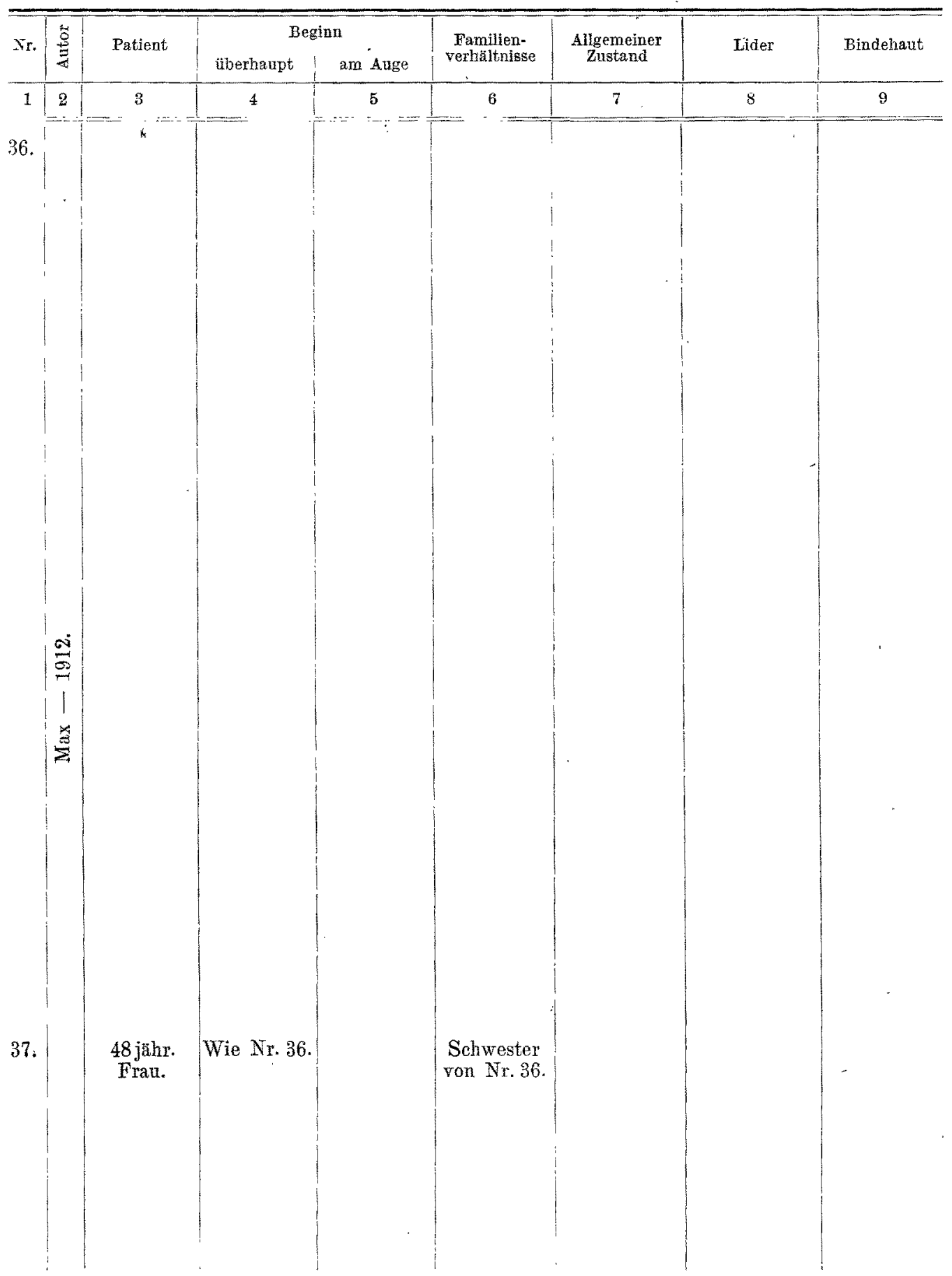


an dem Krankheitsbilde des Xeroderma pigmentosum.

\begin{tabular}{|c|c|c|c|c|c|c|c|}
\hline Limbus & Fornhaut & Lederhaut & $\begin{array}{c}\text { Regenbogen- } \\
\text { heut }\end{array}$ & Tiefere Teile & $\begin{array}{l}\text { Anatomischer } \\
\text { Befund }\end{array}$ & $\begin{array}{c}\text { Therapen- } \\
\text { tische } \\
\text { Versuche }\end{array}$ & Anmerkung \\
\hline 10 & 11 & 12 & 13 & 14 & 15 & 16 & 17 \\
\hline & & & $\begin{array}{l}\text { Pupillarrand } \\
\text { von zartesten } \\
\text { braunen Gre- } \\
\text { websbalkehen } \\
\text { überbrïckt. } \\
\text { Pigmentsanm } \\
\text { am Pupillen- } \\
\text { rande nir- } \\
\text { gends zu } \\
\text { sehen. Nicht } \\
\text { durchleucht- } \\
\text { bar. } \\
\text { L.: Beschaf- } \\
\text { fenheit wie } \\
\text { rechts. } \\
\text { Pupille fast } \\
\text { maximal. Un- } \\
\text { regelmäfig,im } \\
\text { änßern untern } \\
\text { Drittel auf } \\
\text { 1/4mm weiten } \\
\text { Saum hinter } \\
\text { dem Limbus } \\
\text { reduziert. } \\
\text { Stellenweise } \\
\text { Andeutung } \\
\text { von Gliede- } \\
\text { rung sonst } \\
\text { hochgradig } \\
\text { atrophisch. } \\
\text { Am Pupillar- } \\
\text { saum, an zahl- } \\
\text { reichen Stel- } \\
\text { len nur Stro- } \\
\text { mafasern als } \\
\text { Burobentbestau- } \\
\text { von langsova- } \\
\text { len Defekten. }\end{array}$ & & & 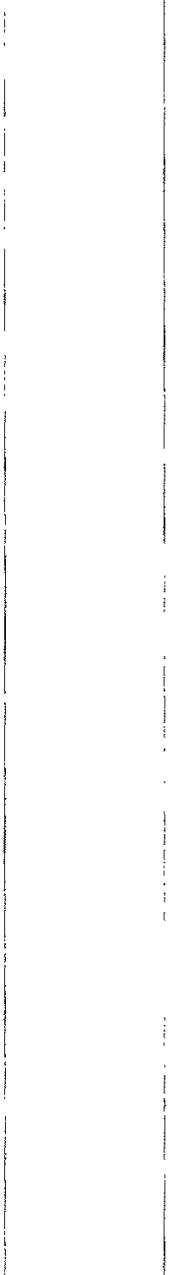 & \\
\hline $\begin{array}{l}\text { Aufder } \\
\text { bärer Tum } \\
\text { der Hom }\end{array}$ & $\begin{array}{l}\text { Whant beider } \\
\text { links die na } \\
\text { t bedeckend } \\
\text { L.: Anf der } \\
\text { Hornhaut } \\
\text { granweiße } \\
\text { Makel. }\end{array}$ & $\begin{array}{l}\text { seits epibul- } \\
\text { asale Hälfte } \\
\text { l. } \\
\text { L.: Sclera } \\
\text { frei vôn Tu- } \\
\text { mor. }\end{array}$ & & $\begin{array}{c}\text { L.: DerTu- } \\
\text { mor medial } \\
\text { nicht ab- } \\
\text { grenzbar,Be- } \\
\text { weglichkeit } \\
\text { nasal stark } \\
\text { einge- } \\
\text { schränt. } \\
\text { R.: Bul- } \\
\text { bus phti- } \\
\text { sisch. }\end{array}$ & & $\begin{array}{l}\text { Abtragung } \\
\text { des Tumors } \\
\text { beiderseits. } \\
\text { R.: Ampu- } \\
\text { tation des } \\
\text { yordern Bul- } \\
\text { busabschnit- } \\
\text { tes. }\end{array}$ & \\
\hline
\end{tabular}




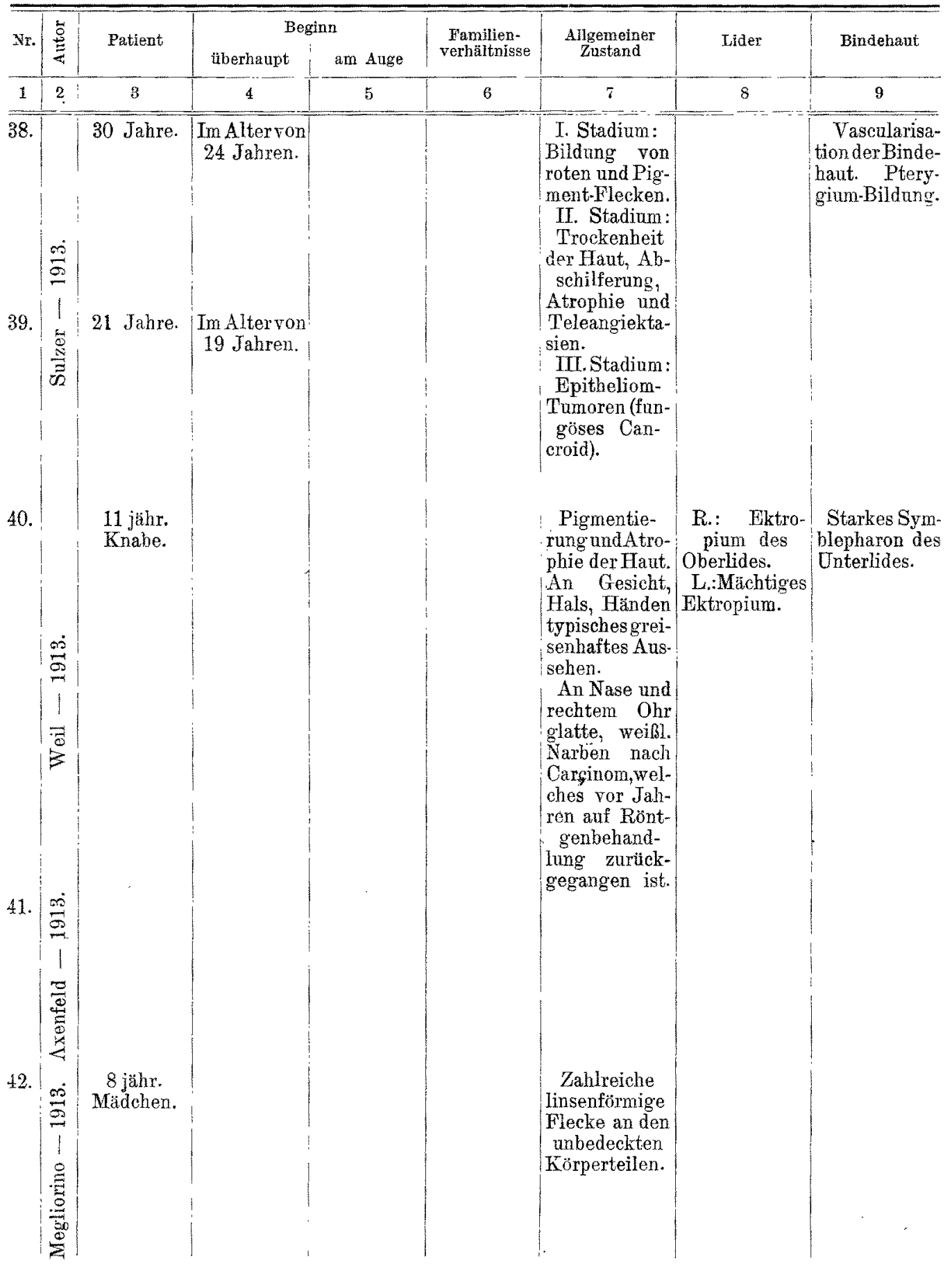


an dem Krankheitsbilde des Xeroderma pigmentosum.

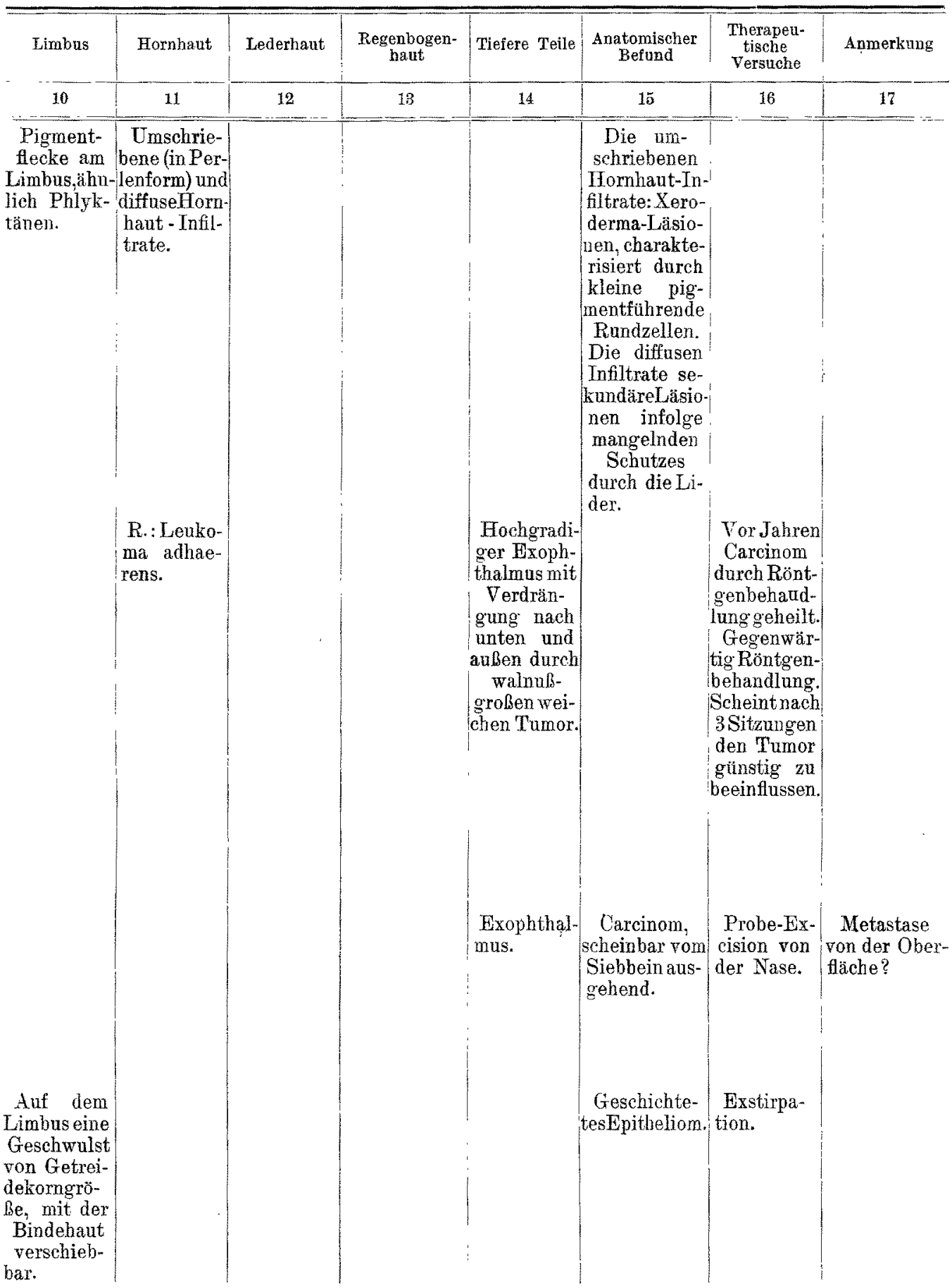




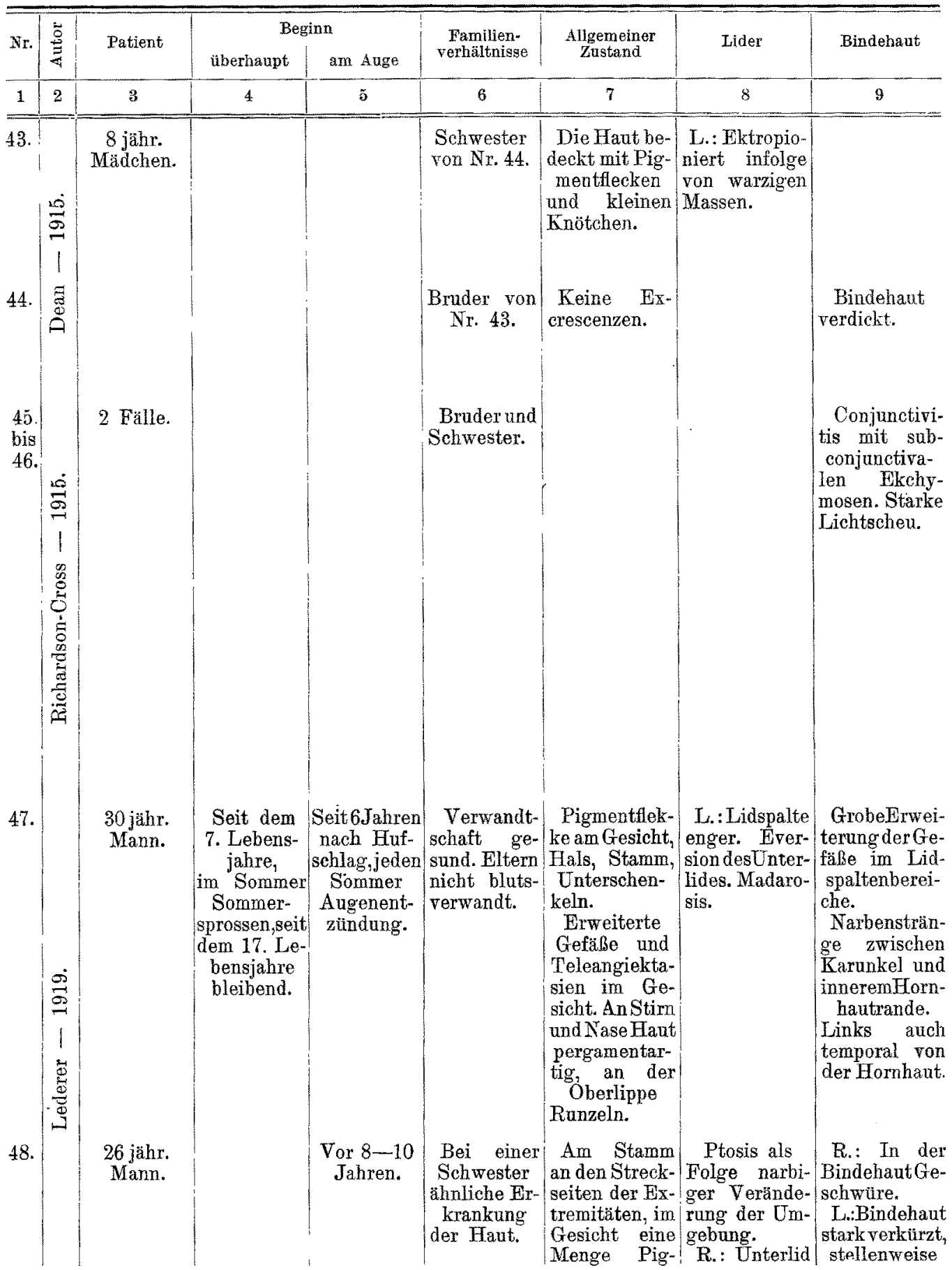


an dem Krankheitsbilde des Xeroderma pigmentosum.

\begin{tabular}{|c|c|c|c|c|c|c|c|}
\hline Limbus & Hornhaut & Lederhaut & $\begin{array}{c}\text { Regenbogen } \\
\text { hatt }\end{array}$ & Tiefere Telle & $\begin{array}{c}\text { Anatomischer } \\
\text { Befund }\end{array}$ & $\begin{array}{l}\text { Therapeu- } \\
\text { tische } \\
\text { Versuch } \theta\end{array}$ & Anmerkung \\
\hline 10 & 11 & 12 & 18 & 14 & 15 & 16 & 17 \\
\hline $\begin{array}{l}\text { Geschwitl- } \\
\text { ste meist im } \\
\text { Limbus. }\end{array}$ & $\begin{array}{l}\text { Auf der } \\
\text { Homhaut } \\
\text { weißliche } \\
\text { Erhöhungen } \\
\text { und allge- } \\
\text { meine Trü- } \\
\text { bung. } \\
\text { Auf der } \\
\text { Hornhaut } \\
\text { gelbweiß- } \\
\text { liche Erhö- } \\
\text { hungen. }\end{array}$ & & 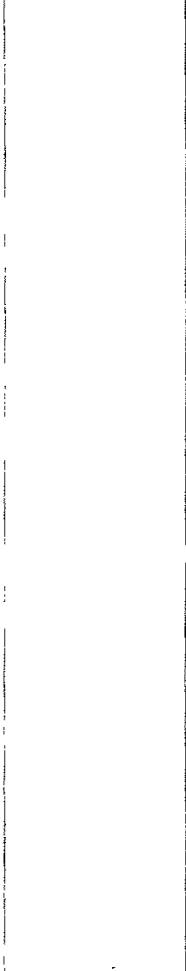 & 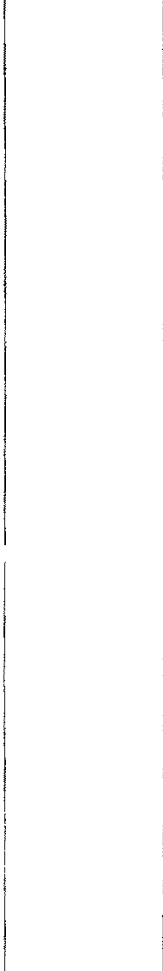 & Carcinom. & \begin{tabular}{|l|} 
\\
Hautkrank- \\
heit der \\
Schwester \\
durch Be- \\
strahlung \\
gebessert, \\
Geschwul- \\
ste entfernt, \\
der Boden \\
abgekratzt \\
und kauteri- \\
siert. Massa- \\
ge mit Kalo- \\
melsalbe. \\
Zustand \\
durch meh- \\
rere Jahre \\
leidlich gut.
\end{tabular} & 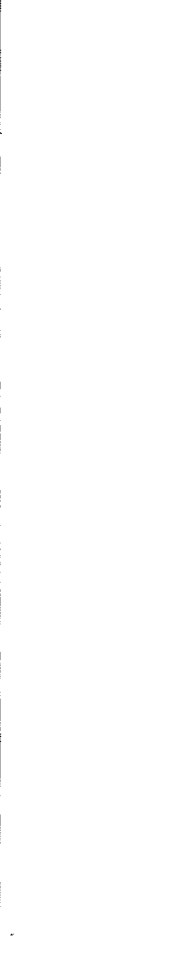 \\
\hline & $\begin{array}{l}\text { R.: Pterygi- } \\
\text { umartiges } \\
\text { Ubergreifen } \\
\text { der Binde- } \\
\text { hautnarbe } \\
\text { aufdieHorn- } \\
\text { haut. }\end{array}$ & & $\begin{array}{l}\text { In der unte- } \\
\text { ren Halfte die } \\
\text { Iris dekolo- } \\
\text { riert. } \\
\text { Substanzar- } \\
\text { mer mit rarefi- } \\
\text { zierterKrause. }\end{array}$ & $\begin{array}{l}\text { L.: Kno- } \\
\text { chentumor } \\
\text { am oberen } \\
\text { Orbitalran- } \\
\text { de. }\end{array}$ & $\begin{array}{l}\text { Bistologisch: } \\
\text { Carcinoma so- } \\
\text { lidum. }\end{array}$ & $\begin{array}{l}\text { Exstirpati- } \\
\text { on des Tu- } \\
\text { mors. }\end{array}$ & $\begin{array}{l}\text { In der Kind- } \\
\text { heit Augen- } \\
\text { entziundung. }\end{array}$ \\
\hline & $\begin{array}{l}\text { R.: Untere } \\
\text { Hialte ma- } \\
\text { kulös ge- } \\
\text { trabt. Spä- } \\
\text { tere Beob- } \\
\text { achtung: }\end{array}$ & & & $\begin{array}{l}\text { Beweglich- } \\
\text { keit beider- } \\
\text { seits nach } \\
\text { oben einge- } \\
\text { schränkt. } \\
\text { L.: Ahduc- }\end{array}$ & $\begin{array}{l}\text { Fistologjsch: } \\
\text { Carcinom. }\end{array}$ & $\begin{array}{c}\text { Wiederhol- } \\
\text { te Exstirpa- } \\
\text { tion.Plastik. } \\
\text { Radiumbe- } \\
\text { strahlung } \\
\text { ohne Erfolg. }\end{array}$ & \\
\hline
\end{tabular}

v. Graefes Archiv fut Ophthalmologie. Bd. 100. 


\begin{tabular}{|c|c|c|c|c|c|c|c|c|}
\hline \multirow{2}{*}{ Nr. } & \multirow{2}{*}{$\stackrel{4}{\stackrel{3}{3}}$} & \multirow{2}{*}{ Patient } & \multicolumn{2}{|c|}{ Beginn } & \multirow{2}{*}{$\begin{array}{l}\text { Familien- } \\
\text { verhältnisse }\end{array}$} & \multirow{2}{*}{$\begin{array}{l}\text { Allgemeiner } \\
\text { Zustand }\end{array}$} & \multirow{2}{*}{ Lider } & \multirow{2}{*}{ Bindehaut } \\
\hline & & & überhaupt & am Auge & & & & \\
\hline 1 & 2 & 3 & 4 & 5 & 6 & 7 & 8 & 9 \\
\hline 48. & & & & & $\begin{array}{l} \\
\\
\text { läppchen } \\
\text { Im wei } \\
\text { Tumor an } \\
\text { Schwellun } \\
\text { talen Drü } \\
\text { am Nasem } \\
\text { linken Wa } \\
\text { zidiv über } \\
\text { in das An } \\
\text { Knoten } \\
\text { rech ts u } \\
\text { tem plasti } \\
\text { Carcinom-1 } \\
\text { neuerlic } \\
\text { Faustgrobe } \\
\text { Jochbein, } \\
\text { Boden der } \\
\text { des harten }\end{array}$ & $\begin{array}{l}\text { mentflecke. } \\
\text { Haut der Nase } \\
\text { narbig. Defek- } \\
\text { te am rechten } \\
\text { Nasenflügel. } \\
\text { Dilatierte } \\
\text { Gefaßße an den } \\
\text { Mundwinkeln } \\
\text { vor denOhren, } \\
\text { am anßseren } \\
\text { Rand desBrau- } \\
\text { enbogens, hin- } \\
\text { ter den Ohr- } \\
\text { Jumoren. } \\
\text { ern Verlaufe } \\
\text { Nacken und } \\
\text { der submen- } \\
\text { en. Rezidive } \\
\text { icken und der } \\
\text { ge, später Re- } \\
\text { Jochbein bis } \\
\text { rum Highmori. } \\
\text { an Tragus, } \\
\text { ter eingeheil- } \\
\text { chem Lappen } \\
\text { lassen, link } \\
\text { les Rezidiv. } \\
\text { Defekt am } \\
\text { Oberkiefer und } \\
\text { Orbita. Fehlen } \\
\text { Gaumens. }\end{array}$ & $\begin{array}{l}\text { fehlend, im in- } \\
\text { nern Lidwin- } \\
\text { kel Ge- } \\
\text { schwulst. } \\
\text { L.: Defekt des } \\
\text { Unterlides, } \\
\text { ibergehend in } \\
\text { einen tiefen, } \\
\text { bis auf den } \\
\text { Knochen rei- } \\
\text { chenden Sub- } \\
\text { stanzverlust. } \\
\text { Beiderseits } \\
\text { in der außere } \\
\text { Oberlides nar } \\
\text { hungen: } \\
\text { Lagophthalmu } \\
\text { Später plastis } \\
\text { Unterlid von } \\
\text { nommen. } \\
\text { R.: Tief ansg } \\
\text { bildung am Ra } \\
\text { lides mit Einb } \\
\text { Lid- und Au } \\
\text { haut. } \\
\text { L.: Ektropiun } \\
\text { benzug. Schlie } \\
\text { Umgebung beid } \\
\text { am rechten i } \\
\text { winkel Rezidiv } \\
\text { Unterlid fehle }\end{array}$ & $\begin{array}{l}\text { tiefe Defekte. } \\
\text { Im weiteren } \\
\text { Verlanf Sym- } \\
\text { blepharon } \\
\text { zum außeren } \\
\text { unteren Qua- } \\
\text { dranten der } \\
\text { Hornhaut. } \\
\text { Bindehaut } \\
\text { katarrhalisch } \\
\text { gerötet. } \\
\text { en Hälfte des } \\
\text { rbige Einzie- } \\
\text { us. } \\
\text { isch gebildetes } \\
\text { Tumor einge- } \\
\text { gehölte Neu- } \\
\text { and des Unter- } \\
\text { beziehung der } \\
\text { ugapfel-Binde- } \\
\text { m durch Nar- } \\
\text { eflich in der } \\
\text { ider Lider und } \\
\text { inneren Lid- } \\
\text { v. } \\
\text { end. }\end{array}$ \\
\hline
\end{tabular}

Die Zụsammenstellung umfaßt 48 Fälle, von denen jedoch der Fall Uhthoffs unter den von Heine beschriebenen Fällen bereits verzeichnet ist, und bei einem der vier Patienten Pergens ausdrücklich die Augen als normal bezeichnet sind. Es kommen also 46 Fälle in Betracht, und wenn mir auch eine Anzahl derselben nur aus Referaten bekannt geworden ist, so bietet die Gesamtheit doch eine solche Fülle von Details, daß sich aus ihnen ein ausreichendes klinisches Bild der Erscheinungsformen des X. p. am Auge zeichnen läßt.

Der Beginn der Erkrankung wird von Greeff in das erste, spätestens zweite Lebensjahr verlegt, während sie nach Velhagen im dritten bis vierten Lebensjahre oder später oder im zwölften bis zwanzigsten Lebensjahre einsetzt. In unserer Zusammenstellung findet sich die Zeit des Beginns $17 \mathrm{mal}$ angegeben, und auch hier lassen sich zwei Gruppen auseinanderhalten. Bei der einen beginnt die Krankheit in der frühesten Jugend bis zum 4.-5. Lebensjahr, in der anderen 


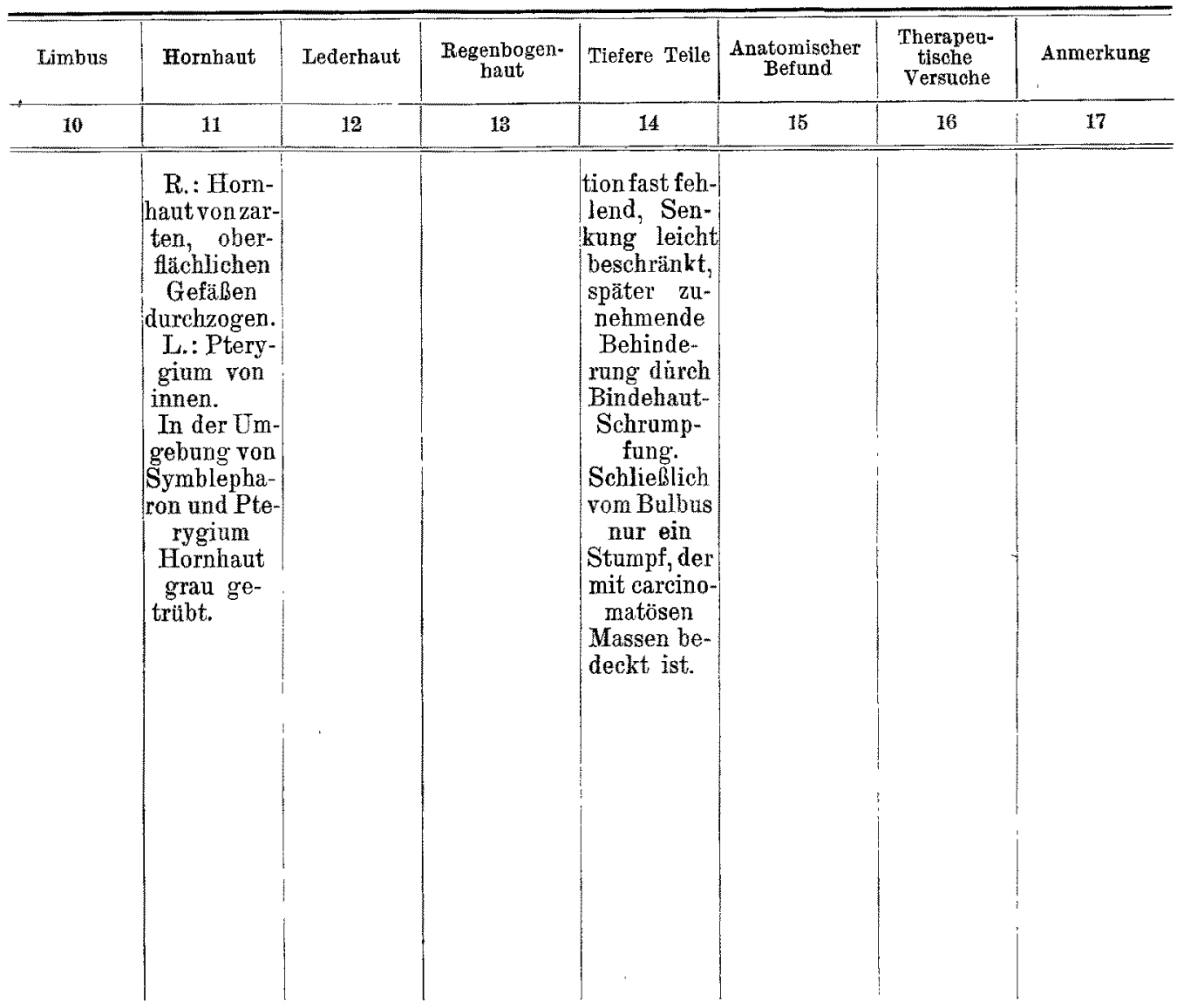

nach der Pubertätszeit bis zum 24. Lebensjahre. Uber den Beginn am Auge finden sich in den bisherigen Arbeiten keine zusammenfassenden Angaben. Unsere Tabelle enthält darüber 7 mal mehr oder weniger genaue Mitteilungen, aus denen zu entnehmen ist, da $\beta$ zwischen dem Beginn der allgemeinen Erkrankung und dem Auftreten der ersten Erscheinungen am Auge ein Zeitraum von 2-10 Jahren verstrichen war, wobei wohl die Annahme erlaubt ist, daß das Auftreten von Pigmentflecken in der Lidhaut im allgemeinen wohl nicht als eine Beteiligung des Auges aufgefaßt worden sein wird.

Utber die familiäre Verbreitung des X. p. geben die bisherigen Veröffentlichungen reichlichen Aufschluß. In unseren, das Auge betreffenden Fällen ist darüber eine Auskunft $22 \mathrm{mal}$ enthalten, $5 \mathrm{mal}$ in negativem Sinne, in 17 Fällen sind Erkrankungen in der nächsten Verwandtschaft angegeben, aus der 7 in der Tabelle selbst mit angeführt sind. Unter unseren Fällen finden sich nicht weniger als 3 Geschwister- 
paare verschiedenen Geschlechtes, und aus der Anamnese der Patienten 10 und 48 geht hervor, daß auch hier Bruder und Schwester von der Krankheit ergriffen worden sind. Die Angabe Peters, die Krankheit trete familiär nur bei männlichen oder nur bei weiblichen Individuen auf, wird demnach durch unsere Zusammenstellung nicht bestätigt.

Niemals aber handelt es sich um Erkrankungen in der Aszendenz, so daß trotz des familiären Auftretens von einer Vererbung der Krankheit nicht gesprochen werden kann, was ja auch begreiflich ist, da das frühzeitige Auftreten zusammen mit den allgemein sichtbaren, schweren und entstellenden Veränderungen eine Fortpflanzung der Befallenen fast immer ausschließen wird.

Über Konsanguinität der Eltern sind zweimal negative und einmal positive Angaben gemacht, mir selbst ist ein Fall von abortiv verlaufenem X. $\mathrm{p}$. bekannt, dessen Eltern blutsverwandt sind.

Ein Blick auf die Rubrik ,allgemeiner Befund" zeigt, daß sich in den mit Augenaffektionen behafteten Fällen alle Formen und alle Stadien der bei X. p. beschriebenen Veränderungen der Haut vorfinden, und daß auch die Lokalisation mit der aus diesen Beschreibungen bekannten übereinstimmt.

An subjektiven Erscheinungen von seiten der Augen sind neben dem Fehlen aller Beschwerden verzeichnet: Lichtscheu, Tränenträufeln, Klagen über Sehstörung.

Wenden wir nun unsere Aufmerksamkeit dem objektiven Befund zu, so werden wir zwischen jenen pathologischen Befunden zu unterscheiden haben, welche bloB eine Lokalisation des Prozesses an den einzelnen Teilen des Auges darstellen, und solchen Veränderungen, welche diesen Teilen als besonderen, bestimmten Funktionen dienenden Einrichtungen eigentümlich sind. Am ausgesprochensten ist dieser Unterschied an den Lidern, deren äußere Bedeckung einen Teil der allgemeinen Hautdecke darstellt.

In der Tat finden wir alle jene Erscheinungsformen der Krankheit, welche aus der Dermatologie bekannt sind, auch auf der Lidhaut lokalisiert: rote Fleckchen, Pigmentflecke, Gefäßèrweiterungen, Narbenherde, Atrophie, Warzenbildung, Geschwülste, geschwüriger Zerfall bis zum Verluste ganzer Lider, wobei die Häufigkeit der Geschwulstbildung eine recht auffallende ist.

Die dem Auge besonderen Eigentümlichkeiten, die an den Lidern beschrieben worden sind, lassen sich unschwer als Folgeerscheinungen der Art und des Grades deuten, in denen die Lider von der Frkrankung ergriffen worden sind. Die Lidränder erscheinen in einer großen Zahl von Fällen betroffen. Rötung, Schwellung, Verdickung, Verklebung der Cilien durch Sekret, Geschwürsbildung, Verstrichensein der Lidkanten sind wiedexholt angegeben, besonders häufig aber das Ausfallen 
der Wimpern. Als Folge der Lidrandentzündungen, hauptsächlich aber der Tumor-, Geschwürs- und Narbenbildung erscheint (in 12 Fällen) Ektropium an einem bis allen vier Lidern verzeichnet, Entropium einmal registriert. Ebenso vereinzelt finden sich Angaben über Ptosis, welche hauptsächlich durch Starrheit und Schwerbeweglichkeit des Lides erzeugt war, und über Lagophthalmus.

Was die Erscheinungen an der Bindehaut betrifft, so ist eine Beteiligung derselben in Form von Injektion bis zu katarrhalischer Entzündung mit Rötung, Schwellung und Schleimabsonderung außerordentlich häufig (unter 28 Angaben über das Verhalten der Bindehaut $22 \mathrm{mal}$ ).

Während aber Hyperämie und entzündliche Veränderungen wohl als Begleiterscheinungen des eigentlichen pathologischen Prozesses aufzufassen sind, sind die zahlreichen, sonst angeführten Symptome als spezifische Äußerungen der Krankheit zu betrachten, deren Erscheinungsformen durch die besonderen Verhältnisse des betroffenen Organs bedingt sind. Analog den Gefäßveränderungen in der Haut finden sich auch in der Bindehaut zweimal Teleangiektasien angegeben. Welcher Hautveränderung die von $\mathrm{Max}$ beschriebenen pingueculaartigen Verdickungen in der Bindehaut an die Seite zu stellen sind, ist jedoch nicht ohne weiteres klar. Die Geschwulstbildung in der Bindehaut ist fünfmal beschrieben worden, davon zweimal zustande gekommen durch Übergreifen vom Lid aus, zweimal als in der Bindehaut primär lokalisiert und einmal als Metastasenbildung aufgefaßt.

Eine ansehnliche Gruppe unter den Bindehautveränderungen bilden die durch Schrumpfung und Narbenbildung erzeugten. Die Schrumpfung der Bindehaut, in 4 Fällen beschrieben, kann sich bis zum völligen Verstreichen des Bindehautsackes entwickeln, in einem Teil der Fälle ist sie mit schwerer Narbenbildung vergesellschaftet, welche das Auftreten von mehr oder weniger ausgebreitetem Symblepharon zur Folge hat, wie es in 6 Fällen beschrieben worden. ist. Während es sich in diesen Fällen mit um die schwersten Formen der Erkrankung handelt, hat eine zweite Form von Narbenbildung das langdauernde Bestehen der Erkrankung gemeinsam. Von Velhagen sind bei 3 seiner Patienten zwischen Tränenkarunkel und innerem Hornhautrand sich hinziehende Narbenstränge beschrieben worden, die sonst nirgend verzeichnet sind, die aber auch ich in meinem Falle 47 an beiden Augen beobachten konnté, an dem einen Auge neben einer beginnenden ähnlichen Narbenbildung auch lateral von der Hornhaut.

Der Limbus kommt hauptsächlich als Ursprungsort von Geschwülsten in Betracht (Fall 11, 18, 42, 45 und 46 und vielleicht auch 16 und 37). Daneben erwähnt nur Sulzer in seinen beiden Fällen Pigmentflecke am Limbus, welche Phlyktänen ähneln.

Von großer Mannigfaltigkeit ist die Art der Beteiligung der Horn- 
haut. Von vornherein auszuschalten aus dem Rahmen der Betrachtung sind die in den Fällen 15 und 47 angeführten Folgen nach in der Kindheit überstandenen, zweifellos ekzematösen Erkrankungen. Es ist fraglich, inwieweit noch andere in den Krankengeschichten angegebene Makeln, wie etwa die im Falle 37, auf den gleichen Ursprung zurückzuführen sind. Dies erhöht aber die Schwierigkeit, aus der großen Zah] der Veränderungen an der Hornhaut jene herauszuheben, welche als Erscheinungsformen des Xerodermaprozesses anzusehen sind, um so mehr als auch die zweifellos spezifischen Produkte an der Hornhant oder in der Nachbarschaft sekundäre Veränderungen exzeugen, welche dadurch wohl mittelbar auf die in Frage stehende Frkrankung zurückzuführen sind, aber nicht als eine Erscheinungsform derselben gedeutet werden können.

So sind wohl jene Trübungen aufzufassen, welche sich, wie in dem Fall 16, an einen die Hornhaut durchsetzenden Tumor anschlieBen oder, wie im Fall 48, ein Pterygium umsäumen, vielleicht auch die Mattigkeit der Oberfläche and in dem Falle 2, im AnschluB an ein Uleus corneae. Andere Fälle bieten zufolge der unzureichenden Beschreibung (6, 17) für die Bewertung der pathologischen Veränderungen keinen genägenden Anhaltspunkt. Mit den Veränderungen in den Nachbarorganen hängen die flügelfellartigen Bildungen zusammen, wie sie auBer in den Symblepharonfällen auch bei den Patienten 38 und 39,47 and 48 beobachtet worden sind.

Die Zahl der Fälle von Geschwürsbildungen auf der Hornhaut ist zu gering, als daß ein Schluß auf die Art der Beziehungen dieses Symptoms zu dem X. p. erlaubt wäre. Einmal handelt es sich um ein Geschwür im innęren oberen Hornhautsektor (Fall 2), das andere Mal (Fall 22) um randständige Geschwürchen. Noch weniger ist für eine derartige Beurteilung das Leucoma adhaerens des Falles 40 verwendbar, von dem im AnschJuB an einen operativen Eingriff entstandenen im Falle 23 gar nicht zu reden.

Nach Ausscheidung aller dieser Fälle bleibt eine Reihe von Beobachtungen übrig, die wohl die Annahme einer Lokalisation des Krankheitsprozesses auf der Hornhaut zulassen. Bei der Durchsicht derselben ist eine auch sonst in der Pathologie der Hornhaut geläufige Sonderung der krankhaften Veränderungen in oberflächliche und tiefe angezeigt. Die oberflächlich auftretenden Affektionen lassen 2 verschiedene Formen erkennen, deren eine den Charakter des Pannus hat. Die Entwicklung desselben ist aus den Krankengeschichten ziemlich klar zi verfolgen. Es ist wohl fraglich ob die im Falle 16 erwähnten kleinen Teleangiektasien als das erste Stadium anzusehen sind, gewiß aber bezeichnen die im Fall 23 beschriebenen GefäBbäumchen, die rom Limbus auf die Randteile der Hornhaut übertreten, die Anfangsformen 
dieses Prozesses, dessen weitere Entwicklung bis zur Bildung eines fleischigen pannusartigen Gewebes auf der Hornhaut, aus eben dieser Krankengeschichte wie aus jenen dẹr Fälle 24,36 und 48 zu ersehen ist.

Die Fälle 23, 34, 38, 39, 43 und 44 weisen eine zweite Form oberflächlicher Erkrankung der Hornhaut auf, die sich charakterisiert durch das Auftreten von kleinen Herden, die als weißliche prominente Infiltrate, als grauweiße locker aussehende Auflagerungen; umschriebene perlenförmige Infiltrate und weißliche oder gelbweißliche Erhöhungen beschrieben werden. In den Fällen 38,39 und 43 ist neben diesen scharf umgrenzten Herden auch noch eine diffuse Trübung beschrieben, von welcher ich im Gegensatz zu Sulzer, welcher die diffuse Infiltration auf mangelnden Schutz durch die Lider zurückführt, annehmen möchte, daß sie nicht bloß eine Begleiterscheinung der herdförmigen Lokalisation des Krankheitsprozesses darstellt, sondern eine direkte Erscheinungsform dieses selbst ist, da eine ähnliche, in dem Falle 36, ohne die kleinen perlenförmigen Infiltrate als aus feinsten Pünktchen bestehend, beschrieben worden ist und in den anderen Fällen von einer Insuffizienz des Lidschlusses nicht die Rede ist. Inwieweit die schon oben erwähnte Mattigkeit der Hornhautoberfläche im Falle 2 die mit einem Ulcus cormeae vergesellschaftet ist, hierher gehört, möchte ich dahingestellt sein lassen.

Neben diesen oberflächlichen Formen findet sich auch eine tiefe Erkrankungsform der Hornhaut in den Fällen 19, 20 und 22 verzeichnet, die teils als parenchymatöse Trübung beschrieben wird, teils als Durchsetzung der Hornhaut mit tiefsitzenden Flecken.

Beispiele für Tumorbildung in der Hornhaut bieten die Fälle 16, 18 und 37. Wir haben es hier zweifellos nicht mit dem Ort der primären Entwicklung zu tun, vielmehr mit dem, auch mit unseren sonstigen Erfahrungen über die Neubildungen der Hornhaut übereinstimmenden Ubergreifen einer im Limbus entstandenen Geschwulst zu tun. Inwieweit hierbei die von Riehl und Sattler angenommene Bildung einer Metastase zu Recht besteht, kann ich nach dem Referat allein nicht beurteilen, doch wird auf die Frage der Metastasenbildung noch eingegangen werden.

Eine Beteiligung der Sclera ist nur in wenigen Fällen angegeben. In dem Falle Greeffs (17) handelt es sich um einen Pigmentfleck, der indes nach dessen weiteren Ausführungen wahrscheinlich nicht der Sclera selbst angehört, sondern der Scleralbindehaut, einmal (Fall 9) um weißgelbliche Wucherungen mit unebener Oberfläche. Von den 5 Fällen, bei denen Tumor der Selera verzeichnet ist, ist in den Fällen 16, 33 und 37 ein Übergreifen der Geschwulstbildung auf die Lederhaut unzweifelhaft, im Falle 20 der Ursprung im Limbus wahrscheinlich, währénd im Falle 10 von einer Neubildung in der Sclera allein die Rede 
ist. Auf jeden Fall handelt es sich in allen Fällen um pathologische Prozesse, welche dem X. p. eigentümlich und demnach als echte Produkte desselben anzusprechen sind.

Von besonderem Interesse sind die Veränderungen in der Iris. Sie sind nur in 3 Fällen beobachtet worden, der erste ist von Elschnig selbst, die beiden anderen aus seiner Klinik beschrieben worden. So gering die Zahl dieser Fälle ist, so gestatten sie doch vermöge der verschiedenen Grade der Irisveränderungen, die sie aufweisen, eine Vorstellung von der Entwicklung des krankhaften Vorganges. Besonders instruktiv ist in dieser Beziehung der von Elschnig beschriebene Fall, der wohl die jüngsten Veränderungen, und diese in verschiedenen Stadien der Entwicklung aufweist. Danach bleibt der Pupillarteil zunächst frei. Die ersten pathologischen Veränderungen weisen im Ciliarteil wahrseheinlich die innerhalb der atrophischen Partien stehengebliebenen Inseln auf, welche ,nicht einfach stehengebliebene Reste des normalen Irisstromas darstellen, sondem kompakter, dunkler gefärbt sind als das Gewebe im nicht veränderten Iristeil"s. Es handelt sich also um das herdweise Auftreten vermehrten Pigmentgehaltes, welches in Analogie zu setzen wäre mit der Bildung von ephelidenähnlichen Pigmentflecken auf der Haut. Diesem Stadium, welches auch mit einer Verdichtung des Gewebes einherzugehen scheint, folgen dann atrophische Vorgänge, deren Ausbreitung die erhaltenen Teile gleichsam abbaut und sowohl zur Depigmentierung als auch zur Substanzverarmung des Gewebes führt. Demzufolge entstehen dekolorierte atrophische Stellen und innerhalb derselben Pigmentinseln, auf deren Kosten sich die substanzarmen entfärbten Partien immer mehr ausbreiten, wenn nicht etwa gleichzeitig mit der Pigmentverdichtung gleich von Anfang an an den dazwischenliegenden Stellen Abnahme des Pigmentgehaltes auftritt.

Ein weiteres Stadium stellt unser Fall 47 dar, in welchem die ganze untere Hälfte gleichmäßig atrophisch erscheint. Von stehengebliebenen Resten dichtern, pigmentreichen Irisstromas innerhalb der Atrophie ist hier nichts wahrzunehmen, und es ist die Frage, ob hier die Atrophie überhaupt in der geschilderten Art zustande gekommen ist und nicht vielmehr gleich von vornherein nur mit atrophischen Vorgängen eingesetzt hat. Jedenfalls aber bildet er anschaulich einen Übergang zu den schweren Veränderungen, welche in dem Falle 36 von Max in die Erscheinung treten. Auch in unserem Falle findet sich noch eine deutliche Gliederung in Ciliarteil, Krause und Pupillarteil, aber in der von der Atrophie ergriffenen unteren Hälfte ist schon deutlich ein Abbau der Krause ausgeprägt, die gleichsam einen Schutzwall bildet gegen das Übergreifen des Prozesses auf die Sphincterpartie. Gleich dem stehengebliebenen Gerüst eines zerstörten Baues ragt ihr zartes Balken- 
werk aus dem substanzarmen Gewebe hervor, aber auch dieses Gerüst ist dem zerstörenden Prozeß verfallen, die Bälkchen sind spärlicher gefügt, verdünnt, in versehiedenem Grade angenagt, an einzelnen Stellen bis zur Loslösung des Zusammenhanges, so daß einzelne mit ihren freien, fadenförmig verdünnten Fnden im Kammerwasser flottieren. Stellenweise sind auch diese Reste von Krause vollständig versehwunden.

Über dieses Stadium hinaus reichen nun die Veränderungen, die der Fall von Ma zeigt. Während an einer Stelle des linken Auges die Gliederung im Ciliarteil, Krause und Pupillarteil noch angedeutet ist, ist von einer solchen in den übrigen Partien sowie am anderen Auge nichts mehr zu erkennen. Die Struktur, die in unserem Falle noch deutlich die Gefäßanordnung erkennen läßt, weist hier nur noch stellenweise spärliche Gefäße auf, ist in der Hauptsache aber vollständig verwischt, die Iris erscheint vollkommen glatt. Allein der atrophische Vorgang ist dabei nicht stehengeblieben, sondern bis zum völligen Schwund des Irisgewebes fortgeschritten, der vom Pupillarrand ausgehend, die Iris an einer Stelle bis auf einen $1 / 4 \mathrm{~mm}$ breiten Saum verschmälert. Dieser Vorgang scheint sich in ähnlicher Weise abzuspielen, wie die Einschmelzung der Krause in unserem Falle. Dafür sprechen die Reste von Irisgewebe, die an einzelnen Stellen des betroffenen Pupillenrandes noch zu sehen sind in Form von zarten Gewebsbälkchen, die, den Pupillenrand überbrückend, benachbarte Tristeile miteinander verbinden. In den früheren Stadien, ausschließlich das Stroma betreffend, ergreift in den Endstadien die Zerstörung auch das Pigmentblatt, zu allerletzt, wie aus der Lichtundurchlässigkeit der erhaltenen Iristeile zu ersehen ist.

Miteinander zusammengehalten bieten diese 3 Fälle Veränderungen in der Iris dar, die unschwer in Analogie zu setzen sind mit den Vorgängen in der Haut, zumal wenn man mit Kaposi und Neisser das Wesen der Erkrankung in einem mit Pigmentbildung einhergehenden Prozeß der Atrophie erblickt, und die dünne, glatte, strukturlose Iris mit dem Schwund der Gefäße wie sie Max in seinem Falle beschreibt, erinnert unmittelbar an die gefäßlosen, atrophisch glatten, verdünnten Hautpartien ohne Falten und Furchen. Die bisher beschriebene Beteiligung der Iris an dem Krankheitsbilde des X. p. darf also mit Recht als eine echte Erscheinungsform dieser Krankheit gewertet werden, gleich wie Löwenstein in dem von Müller als Vitiligo iridis bezeichneten Krankheitsbilde die Folgen einer in der Iris lokalisierten Variola. erkannt hat.

Über die Veränderungen in den tieferen Teilen des Auges ist in den Krankengeschichten außer Durchwucherung des Strahlenkörpers durch eine Neubildung im Falle 18 nur die Angabe über eine $1 / 2$ P. breite naevusartige Pigmentierung im Anschluß an die Papille im Falle 36 
enthalten. So sehr die Pigmentablagerung mit dem Wesen des $X$. p. vereinbart ist, so ist der beschriebene Befund doch ein so häufiges Vorkommnis, daß es sich wohl nur um ein zufälliges Zusammentreffen handeln kann, um so mehr als er in der Reihe der beschriebenen Fälle rereinzelt dasteht.

In den Fällen 37 und 48 haben die destruktiven Wirkungen der Tumorausbreitung bis zur Phthisis bulbi geführt. Sonst hatte die Ausbreitung die Beteiligung der extrabulbären Gebilde der Orbita zur Folge, wie in den Fällen 2, 16, 33 und 37, während eine solche in den Fällen 40 und 41, in welchen es zu Exophthalmus gekommen ist, von einer Erkrankung der Nachbarorgane ausgegangen zu sein scheint.

Eine Beteiligung des Knochens verzeichnen die Fälle 27, bei welchem das Periost des Orbitalrandes verdickt erscheint, und unsere Fälle 47 und 48 , in welchen der Knochen von der Geschwulstbildung direkt betroffen ist.

Außer den durch die Beteiligung der Hornhaut verursachten Sehstörungen war die Funktion hauptsächlich in Form einer Beweglichkeitsbeschränkung beeinträchtigt, die teils durch die narbigen Veränderungen und Schrumpfungsvorgänge an Lidern und Bindehaut, teils durch die Raumbeengung in der Orbita oder das. Ergriffensein der Augenmuskeln von den Neubildungen hervorgerufen war.

Neben den versuchten therapeutischen Maßnahmen gegen die Hauterkrankung, die durchwegs ergebnislos geblieben sind, findet sich nur die Angabe von Richardso n Cross, daß bei dem einen seiner Patienten durch Röntgenbestrahlung eine Besserung der Hautkrankheit erzielt worden ist. Die therapeutischen Versuche am Ange waren ausschließlich gegen die Folgen der Narbenbildung und vor allem gegen die Geschwulstbildung gerichtet. In erster Reihe gelangte die Exstirpation der Tumormassen zur Verwendung. Einmal war dieselbe verbunden mit Ausräumung des Orbitalinhaltes, zweimal mit Entfernung des Angapfels und einmal mit Abtragung seines vorderen Abschnittes. Von den sonstigen 20 Fällen von Tumorentfermung betrafen 9 Lidgeschwülste, 9 epibulbäre Geschwülste und unsere beiden Fälle einen Knochentumor. Nur in dem Falle 23 wurde von Ischreyt primär auch Ätzung mit Chromsäure angewendet, und Weil berichtet von der Behandlung eines retrobulbären Tumors mit Röntgenstrahlen bei einem Patienten, bei dem schon Jahre zuvor ein Hautcarcinom durch Röntgenbehandlung geheilt worden war.

Sonst gelangte Röntgenbehandlung in den Fällen 20 und 46, in dem letzteren auch Massage mit Kalomelsalbe im Anschluß an die Entfernung der Tumoren zur Anwendung. Die im Falle 48 angewandte Radiumbestrahlung betraf Carcinomknoten, die nicht am Auge selbst lokalisiert waren. 
Von dem Ergebnis der therapeutischen Maßnahmen ist nur in einer geringen Zahl der Fälle die Rede. Von einer „Ausheilung mit Bildung eines Pseudopterygiums" berichtet Velhagen nach Exstirpation eines in einer Kapsel eingeschlossenen epibulbären Tumors, und in dem Falle Weils blieb ein mit Röntgenbestrahlung behandeltes Lidearcinom auch noch nach Jahren geheilt. Auch Greeff berichtet von dem Patienten 16, bei dem der Bulbus enucleiert worden war, daß nach $5 / 4$ Jahren kein Rezidiv aufgetreten ist, gleichwie Lesser noch nach einem Jahre kein Rezidiv sah. Demgegenüber verzeichnet Lukasiewicz epitheliale Nachschübe nach Exstirpation eines Bindehauttumors, La mborelle ein Rezidiv nach Entfernung eines vorn Limbus ausgehenden und Cuperus ein solches nach einem Lidcarcinom and die Krankengeschichte des Falles 48 schildert einen verzweifelten, erfolglosen Kampf ron Exstirpation und Plastik mit immer neuen Rezidiven.

Ninmt man nun noch hinzu, daß in den meisten Krankengeschichten von einem Dauererfolg der Exstirpation nicht berichtet wird, so gewinnt man den Eindruck, daß es sich in der größten Zahl der Fälle um Tumoren mit recht bösartigem Charakter handelt, sowohl was ihre Ausbreitungsfähigkeit als ihre Neigung zu Rezidiven betrifft.

Utber die Frage der Metastasenbildung sind die Angaben recht spärlich. Cuperus stellt bei seinen Patienten ausdrücklich fest, daß bis zum Tode, welcher durch Kachexie erfolgt ist, keine Metastasen aufgetreten waren. Die am Auge selbst beobachteten Geschwülste werden bei Fall 18 von Sattler als Carcinommetastasen bezeichnet, und Axenfeld stellt es der Überlegung anheim, ob das anscheinend vom Siebbein ausgehende Carcinom, das zu Exophthalmus führte, nicht eine Metastase von der Oberfläche darstellt. Demgegexüber stellt es Velhagen als wahrscheinlich hin, daß der von ihm exstirpierte epibulbäre Tumor an dem Orte seiner Entwicklung aus einem Naevus oder einem anderen hier versprengt gewesenen Keim entstanden ist.

Über die Natur der Geschwülste, welche Greeff als Carcinome bezeichnet, hat sich, soweit die epibulbären in Frage kommen, Velhagen ausführlicher ausgesprochen. Er kommt auf Grund des histologischen Befundes des in seinem Falle gewonnenen Präparates zu der Ansicht, daß es sich um einen Tumor handle, der mit größerem Recht zu den Carcinomen als zu den Sarkomen gerechnet werden muB, und den er als Medullarkrebs bezeichnen möchte, weist aber auf die Schwierigkeiten hin, bei den von den Naevis ausgehenden Tumoren eine Scheidung zwischen Sarkomen und Karzinomen durchzuführen. Demgegenüber bleibt es auffallend, daß in den von uns zusammengestellten Fällen am Auge nur ein einziges Mal Sarkom konstatiert worden ist, und zwar von Lešer, der bei einem von der Nase desselben Patienten gleichzeitig ențfernten Tumor das histologische Bild eines Carcinoms fand. Die 
Sarkomdiagnose in den Fällen 11 und 13 bezog sich nur auf Hauttumoren, ebenso betrifft der Carcinombefund in dem Falle Elschnigs eine Neubildung der Wange und in dem Falle Axenfelds ein von der Nase entferntes Geschwulststück. Von den übrigen 15 Geschwülsten mit pathologisch-anatomischer Bezeichnung gehören 7 den Lidern an, unser Fall 47 betrifft den Knochen und 7 haben den Bulbus oder Teile desselben ergriffen. Alle diese werden bis auf den Fall von $\mathrm{Hanke}$ welcher die aus kleinkalibrigen Gefäßen bestehende Geschwulst als Peritheliom führt, als Carcinome bezeichnet (die von Brandès und Migliorino als Epitheliom). Allerdings erwähnt auch Ischreyt, daß in seinem als Carcinom diagnostizierten Präparat Form und Lage der Zellen sarkomähnlich sind. Im allgemeinen stimmen also die $\mathrm{Be}$ funde am Auge mit den Angaben Un nas hinsichtlich der Haut überein, welche dahin gehen, daß auf derselben Carcinome entstehen, während Sarkome sehr selten sind. Außerhalb der Reihe dieser Befunde steht das Untersuchungsergebnis Heines, der in einer von dem Oberlid des einen seiner beiden Patienten abgetragenen Verruca außer elastischen Fasern nichts Besonderes fand. Es dürfte sich da nicht um den später von Uhth off beobachteten Fall handeln, bei dem dieser beide Unterlider zerstört fand.

Die Ausbeute an sonstigem histologischem Material ist verhältnismäBig gering. Sie betrifft einmal das pterygiumartige Symblepharon, das Hein e excidierte und als epithelialisierte Bindehautfalte mit mäßiger Vermehrung der elastischen Elemente in teils lockerem, teils derberem Bindegewebe bestimmte. Von der Hornhaut entfernte Clausen vom unteren Rand bis zur Mitte der Pupille reichende Auflagerungen, welche sich als verdickte auf die Hornhaut vorgeschobene Bindehaut ohne carcinomatöse Entartung erwiesen, und Sulzer umschriebene perlenförmige Hornhautinfiltrate, welche er als Xerodermaläsionen bezeichnet, charakterisiert durch kleine pigmentführende Rundzellen. Die von Lesser von der Sclera entfernten gelbweißen Wucherungen hatten epithelartigen Charakter.

Hinsichtlich der Ätiologie vermögen die Fälle mit Augenbefund nicht viel Neues zur Klärung beizutragen. Unter den Patienten befanden sich ebenso kräftige und gutgenährte, wie schwächliche und zarte, für konstitutionelle Frkrankungen ergaben sich keine Anhaltspunkte. Uber das hereditäre und familiäre Moment war schon oben die Rede. Im allgemeinen kehrt die Angabe immer wieder, daß von der Krankheit nur die von der Bekleidung nicht geschützten Partien befallen worden sind, und Ischreyt, Cuperus, Heine und Brandès sprechen sich für den Finfluß der Sonne und des Lichtes als maßgebenden Faktor aus. Heine begründet diese seine Anschauung direkt mit den Befunden am Auge, an dem gerade die dem Lichte am meisten ausgesetzten 
Stellen die Prädilektionsstellen der Krankheitsherde darstellen. Auch uns scheint ein Überblick über die zusammengestellten Fülle in diesem Sinne zu sprechen. Außer den schon von Heine herangezogenen Symblepharonbildungen bevorzugen auch die übrigen Krankheitssymptome im allgemeinen den Lidspaltenbezirk in nicht zu verkennender Weise. Am deutlichsten ist das ersichtlich an den von Velhagen beschriebenen und auch von mir beobachteten Narbenzügen in der scleralen Bindehaut, und hier besonders in der inneren Hälfte. Für den Pannus ist die Beschränkung auf die untere Hornhauthälfte geradezu charakteristisch, die auch für die kleinen, umschriebenen, prominierenden Infiltrate den Lieblingssitz abgibt. In diesem Sinne spricht auch die Beschränkung der Irisatrophie in dem von mir beschriebenen Falle auf die untere Hälfte, ebenso wie in dem Falle 36, die Veränderungen an Bindehaut und Hornhaut nux den Lidspaltenbezirk betreffen und auch die Veränderungen an der Iris hier am stärksten sind. Es scheinen somit die Befunde am Auge tatsächlich die Annahme zu stützen, daß dem Sonnenlicht wenigstens für die Lokalisation der Xermodermaaffektionen ein entscheidender Einfluß zukommt.

Von dem Ausgang der Krankheit ist nur in 2 Krankengeschichten die Rede. Die Patientin Cuperus' ist an Kachexie gestorben, der eine von Greeffs Patienten an Schlaganfällen unter zunehmender allgemeiner Schwäche. Es entspricht das auch den Angaben der Dermatologen, daß der Tod durch allgemeine Kachexie herbeigeführt zu werden pflegt.

So bieten die Befunde an den Augen vieles von der Erkrankung der. Haut her Bekanntes, zum Teil der Lokalisation entsprechend modifiziert, daneben aber auch zahlreiche dem Auge eigentümliche Frscheinungen, deren genauere, namentlich durch histologische Untersuchungen vervollständigte Kenntriis mit der Zeit auch ihrerseits zum Verständnis der Pathologie des X. p. beitragen dürfte. 